\title{
Interdecadal Variation in the Synoptic Features of Mei-Yu in the Yangtze River Valley Region and Relationship with the Pacific Decadal Oscillation
}

\author{
Bo Sun, HuiJun WANG, AND BotaO ZHOU \\ Collaborative Innovation Center on Forecast and Evaluation of Meteorological Disasters/Key Laboratory of Meteorological \\ Disasters, Ministry of Education/Joint International Research Laboratory of Climate and Environment Change, \\ Nanjing University of Information Science and Technology, Nanjing, and Nansen Zhu International Research \\ Centre, Institute of Atmospheric Physics, Chinese Academy of Sciences, Beijing, China \\ HUA LI \\ Nansen Zhu International Research Centre, Institute of Atmospheric Physics, Chinese Academy of Sciences, Beijing, China
}

(Manuscript received 8 January 2019, in final form 15 May 2019)

\begin{abstract}
This study introduces a multivariable covariance index (MVCI) to illustrate the synoptic features of mei-yu in the Yangtze River valley (YRV) region, which contains information of three indicators of mei-yu including precipitation, surface relative humidity, and tropospheric vertical motion. The interdecadal variation in the synoptic features of mei-yu during 1961-2016 is investigated using the MVCI. The date of mei-yu peak and the intensity of mei-yu underwent noticeable interdecadal variations over past decades, which are characterized by a delayed (relatively early) mei-yu peak and a relatively large (small) mei-yu intensity during 1985-97 (1961-80 and 2006-16). The mechanisms of these interdecadal variations are further discussed. The interdecadal variation in the date of mei-yu peak is mainly modulated by the meridional water vapor transport over eastern China during June, which may be partially attributed to an influence of the Pacific decadal oscillation (PDO) on the clockwise gyre over the North Pacific during boreal summer. The interdecadal variation in mei-yu intensity is associated with the interdecadal variation of tropospheric vertical motion over the YRV region during boreal summer, which may be partially attributed to an interaction between the PDO and the large-scale tropical east-west circulation during boreal summer. In addition, the interdecadal variation in the water vapor flux budget and relative humidity over the YRV region also exerted an impact on the interdecadal variation of mei-yu intensity in the YRV region.
\end{abstract}

\section{Introduction}

Climatically, the mei-yu (i.e., plume rain) is characterized by persistent rainy, humid, and muggy weather in the Yangtze River valley (YRV) and Huaihe River valley (HRV) regions of China from mid-June to midJuly. According to the China Meteorological Administration, the precipitation amount during the mei-yu period generally accounts for $30 \%-40 \%$ of the annual total precipitation in the YRV and HRV regions (http:// www.cma.gov.cn/2011xzt/2016zt/20160428/2016042803/ 201607/t20160714_316772.html). An anomalous mei-yu could cause severe flood or drought in the YRV and HRV regions (Shen et al. 2007). Hence, the interannual and interdecadal variation of mei-yu has been one of

Corresponding author: Botao Zhou, zhoubt@nuist.edu.cn the focuses of meteorologists (e.g., Ding et al. 2007; Si et al. 2009; Sampe and Xie 2010; Li et al. 2018, 2019).

Essentially, the mei-yu is a reflection of the northward advancement of the East Asian summer monsoon (EASM) over East Asia, which causes a northward shift of the rainband from South China to North China via the YRV and HRV regions (Ding et al. 2007; Si et al. 2009). Most of previous studies focused on the onset date and duration of the mei-yu period and precipitation amount during the mei-yu period, where the onset date and duration of the mei-yu period were generally identified based on a standard defined by the China Meteorological Administration (Ding et al. 2007; Li et al. 2019). For instance, Wang et al. (2009) suggested that a warm (cold) phase of central Pacific El Niño-Southern Oscillation (ENSO) in spring may induce a delayed (earlier) mei-yu onset in the YRV and HRV regions. Li and Zhang (2014) found that 
different configurations of East Asian subtropical and polar jets could exert different impacts on the precipitation amount during the mei-yu season of the YRV and HRV regions. Recently, Li et al. (2019) proposed that a strong South Asian anticyclone in April heralds an earlier mei-yu onset in the YRV and HRV regions.

The mei-yu criteria proposed by the China Meteorological Administration are mainly defined based on only one indicator (i.e., precipitation). However, using precipitation as the metric of mei-yu may be not sufficient to comprehensively reflect the features of mei-yu, because the enhanced convective activity (Zhou et al. 2004; Sampe and Xie 2010) and the increased humidity as well as the associated meridional humidity gradient (Tanaka et al. 2007; Cui et al. 2009) over the YRV and HRV regions during the mid-to-late June and early July are also important features of mei-yu. The enhanced convective activity is closely associated with the persistent cloudy weather and depression over the YRV and HRV regions during the mei-yu period (Zhou et al. 2004; Ninomiya and Shibagaki 2007; Sampe and Xie 2010), while the increased humidity may significantly impact human health and thermal comfort during the mei-yu period (Robinson 2001; Luber and McGeehin 2008; Gao et al. 2018). Both the convective activity and the atmospheric humidity are important influential factors of precipitation in the YRV and HRV regions during the mei-yu period (Cui et al. 2009; Sampe and Xie 2010). The synoptic evolution of convective activity reflects the synoptic evolution of dynamic process in the atmosphere associated with mei-yu (Sampe and Xie 2010); the synoptic evolution of atmospheric humidity synthetically reflects the information of large-scale water vapor transport (WVT), atmospheric water vapor content, and air temperature associated with mei-yu, because the large-scale WVT and the atmospheric water vapor content determine the actual vapor pressure and actual specific humidity over the YRV and HRV regions (Sun et al. 2011), while the air temperature determines the saturation vapor pressure and saturation specific humidity in the atmosphere over the YRV and HRV regions (Held and Soden 2006). Observations and numerical simulations indicate that under global warming, the humidity and convective activity in the atmosphere have undergone and would continue to experience distinct variations around the globe (Held and Soden 2006; Vecchi and Soden 2007; Trenberth 2011; Sun and Wang 2017; Sun 2018). These variations in atmospheric humidity and convective activity are generally characterized by an increase in the global atmospheric moisture content and a weakening in the tropical circulation (Held and Soden 2006; Vecchi and Soden 2007; Trenberth 2011; Huang et al. 2017; Hu et al. 2018). As for the YRV and HRV regions, the interdecadal variation of atmospheric humidity and convective activity and their exertion on the interdecadal variation of features of mei-yu have not been well understood. Thus, a simultaneous consideration of precipitation, convective activity, and atmospheric humidity is conducive to better illustrating and understanding the variability of features of mei-yu than only considering precipitation.

Furthermore, it has been widely found that during past decades, the summer climate in eastern China has undergone significant interdecadal changes in the late 1970s, the early 1990s, and the late 1990s (Wang 2001; Ding et al. 2008; Wu et al. 2010; Sun et al. 2011; Zhu et al. 2011, 2015; Sun and Wang 2015). By contrast, there is a lack of knowledge of the interdecadal variation of meiyu and associated mechanisms. Specifically, Ge et al. (2008) identified the 20-30-yr and 40-yr cycles of the mei-yu period as well the relationship between the length of the mei-yu period and EASM on the decadal time scales. Si et al. (2009) revealed an interdecadal increase (decrease) of precipitation in the HRV (YRV) region during the mei-yu season after the late 1990s. Li et al. (2018) analyzed the interdecadal variability of the intensity and position of East Asian mei-yu-baiu fronts. Notwithstanding the aforementioned studies, the interdecadal variation in the synoptic features of mei-yu over the YRV region remains unclear.

Thus, this study aims to investigate the interdecadal variation in the synoptic features of mei-yu in the YRV region $\left(28^{\circ}-32^{\circ} \mathrm{N}, 110^{\circ}-123^{\circ} \mathrm{E}\right)$ during $1961-2016$ based on a new metric utilizing three mei-yu indicators: precipitation, surface relative humidity, and tropospheric vertical motion. The reason this study focuses only on the YRV region instead of the YRV and HRV regions is because previous studies suggested quite different interdecadal variations of summer climate in the YRV and HRV regions (Si et al. 2009; Sun et al. 2011; Zhu et al. 2011).

The outline of this paper is as follows. Section 2 describes the data and methods used in this study. Section 3 introduces a new index to illustrate the synoptic features of mei-yu, and the interdecadal variation in the synoptic features of mei-yu is examined using this index in this section. The mechanism underlying the interdecadal variation in the date of mei-yu peak is investigated in section 4 . The mechanisms of the interdecadal variation in the intensity of mei-yu are discussed in section 5 . Section 6 provides conclusions and discussion.

\section{Data and methods}

\section{a. Data}

The daily mean data of precipitation, surface relative humidity, and surface temperature are derived from the CN05.1 dataset (Wu and Gao 2013), which is an updated 
version of the $\mathrm{CN} 05$ dataset ("CN" is an abbreviation for China; " 05 " represents a resolution of $0.5^{\circ} \times 0.5^{\circ}$ ) and which has a resolution of $0.25^{\circ} \times 0.25^{\circ}$. The CN05.1 dataset is constructed based on over 2400 stations in China. This quality-controlled dataset has been widely used for studying climate variability in China (e.g., $\mathrm{Xu}$ et al. 2009; Sun and Wang 2015, 2017, 2018, 2019; Chen et al. 2017; Li et al. 2017).

The daily and monthly mean data $\left(2.5^{\circ} \times 2.5^{\circ}\right)$ of zonal and meridional winds, specific humidity, and vertical velocity $(\omega)$ at eight pressure levels $(1000,925,850,700,600$, 500,400 , and $300 \mathrm{hPa}$ ) and surface pressure are derived from the National Centers for Environmental Prediction (NCEP)-National Center for Atmospheric Research (NCAR) reanalysis (Kalnay et al. 1996). The monthly mean sea surface temperature $(\mathrm{SST})$ data $\left(2^{\circ} \times 2^{\circ}\right)$ are derived from the NOAA Extended Reconstructed SST V4 (B. Huang et al. 2015). The monthly Pacific decadal oscillation (PDO) index is derived from the Joint Institute for the Study of the Atmosphere and Ocean (http://research.jisao.washington.edu/pdo/PDO.latest).

\section{b. Methods}

A 5-day running mean is performed for the daily data used in this study before all computations to remove the day-to-day variability and to better illustrate the synoptic evolution of meteorological elements. The vertically integrated WVT was calculated by integrating the water vapor flux from the surface to the $300-\mathrm{hPa}$ pressure level using the data of specific humidity and zonal and meridional winds for eight pressure levels $(1000,925,850,700$, $600,500,400$, and $300 \mathrm{hPa}$ ) (Simmonds et al. 1999). A linear regression analysis is conducted to compute the climate anomalies regressed on the 5-yr running mean time series of PDO index for boreal summer. An empirical orthogonal function (EOF) analysis was performed to examine the dominant mode of the interdecadal variation of the tropical vertical motions, using the 5-yr running mean time series of $500-\mathrm{hPa} \omega$. The significance of regression coefficients and correlation coefficients for 5-yr running mean time series is estimated using a Monte Carlo test based on 5000 experiments for 5-yr running mean random time series (Zhao and Han 2005). The linear trends in the time series were removed before the aforementioned linear regression and EOF analysis were performed. In this study, the summer refers to the boreal summer [May-August (MJJA)].

The variability of relative humidity $(\mathrm{RH})$ depends on the saturation specific humidity $\left(q_{s}\right)$ and actual specific humidity $(q)$, where $\mathrm{RH}=\left(q / q_{s}\right) \times 100 \%$. To examine the influences of saturation specific humidity and actual specific humidity on the variability of relative humidity, the interdecadal variation in saturation specific humidity and actual specific humidity are analyzed. Following Song et al. (2012), an empirical Clausius-Clapeyron equation is used to estimate the saturation vapor pressure $\left(e_{s}\right)$ and saturation specific humidity $\left(q_{s}\right)$ based on air temperature:

$$
\begin{aligned}
e_{s} & =6.11 \exp \left[\frac{a(T-273.16)}{(T-b)}\right], \\
q_{s} & =\frac{0.622 e_{s}}{\left(p-0.378 e_{s}\right)}
\end{aligned}
$$

where $a=17.56, b=35.86, T$ represents absolute temperature, and $p$ represents air pressure.

\section{Interdecadal variation in the synoptic features of mei-yu}

\section{a. The multivariable covariance index}

As mentioned before, the variability of features of mei-yu is associated with the variability of precipitation, humidity, and vertical motion. An index synthesizing the information of the three indicators of mei-yu could be conducive to better illustrating and understanding the variability of features of mei-yu than simply using the precipitation as a metric of mei-yu. Particularly, Li et al. (2018) analyzed the variability of the East Asian meiyu-baiu fronts using a suite of indices based on the equivalent potential temperature and its meridional gradient, suggesting that a consideration of factors except for precipitation may contribute to a comprehensive understanding of the features of mei-yu.

To reasonably and clearly illustrate the synoptic features of mei-yu in the YRV region, this study attempts to introduce an index to comprehensively reflect the synoptic evolution of precipitation, humidity, and convective activity over the YRV region during the mei-yu period. Specifically, the surface relative humidity is used to denote the atmospheric humidity considering that a high relative humidity is an essential condition for the occurrence of precipitation and that the relative humidity is an important influential factor of the human thermal comfort condition during the mei-yu period (Gao et al. 2018). Based on previous studies (e.g., Rhome et al. 2000; Norris and Iacobellis 2005; Wyant et al. 2006; Jeong et al. 2008; Manganello et al. 2012; Huaman and Schumacher 2018), the 500-hPa $\omega$ is used to denote the convective activity. Before introducing this index, an overview for the climatic spatiotemporal features of mei-yu is provided as follows. Generally, the mei-yu is mainly featured by positive anomalies in precipitation and surface relative humidity and ascending motion over the YRV region with respect to summer 
(a)
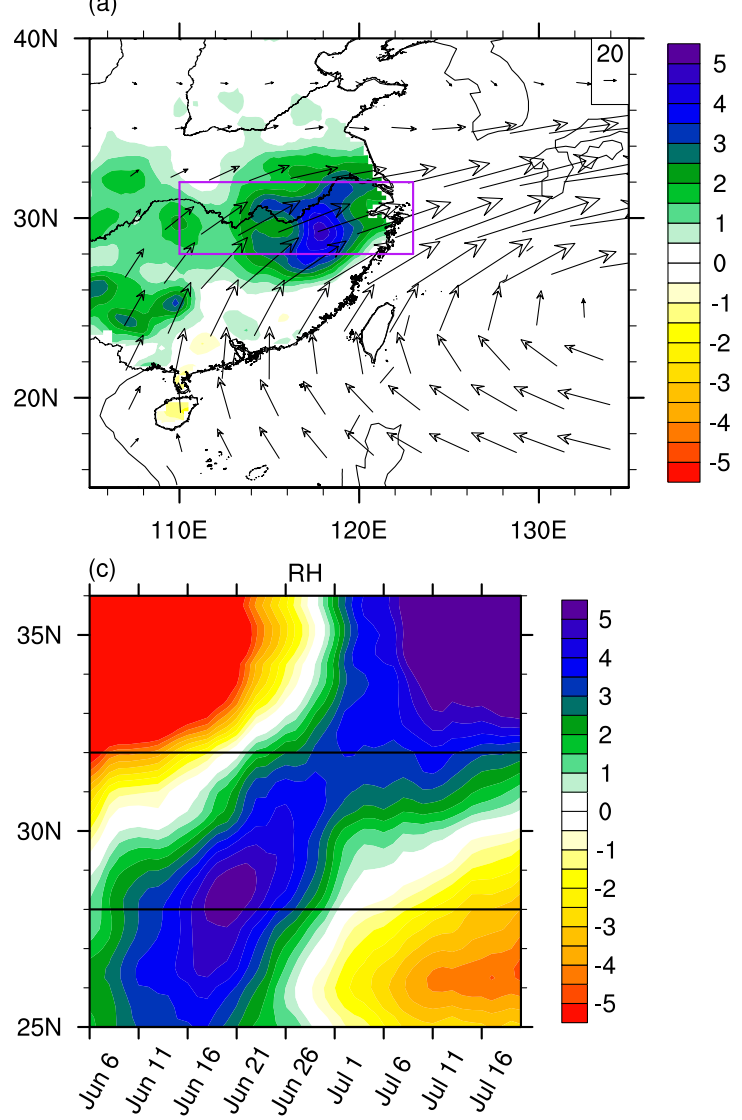
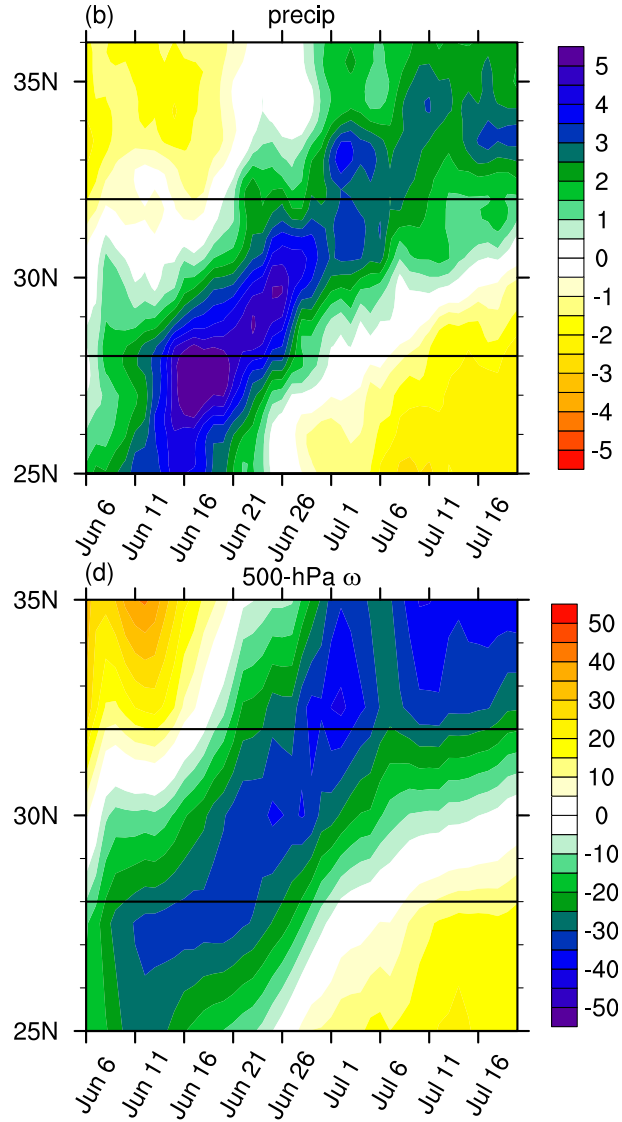

FIG. 1. (a) Anomalies of vertically integrated WVT (vector; unit: $\mathrm{kg} \mathrm{m}^{-1} \mathrm{~s}^{-1}$ ) and precipitation (shading; unit: mm day ${ }^{-1}$ ) during 15 Jun-10 Jul with respect to MJJA climatology for 1961-2016. Time-latitude section of zonal mean anomalies of (b) precipitation (unit: $\mathrm{mm} \mathrm{day}^{-1}$ ), (c) surface relative humidity (unit: \%), and (d) 500-hPa $\omega$ (unit: $10^{-3} \mathrm{~Pa} \mathrm{~s}^{-1}$ ) within $110^{\circ}-123^{\circ} \mathrm{E}$ during 6 Jun-20 Jul with respect to MJJA climatology for 1961-2016. The purple rectangle in (a) represents the domain of YRV region. The horizontal lines in (b)-(d) denote the latitudinal range of YRV region $\left(28^{\circ}-32^{\circ} \mathrm{N}\right)$.

climatology. Figure 1 shows the climate anomalies associated with the synoptic evolution of mei-yu for 19612016. Positive anomalies of precipitation occur in the YRV region during 15 June-10 July, which are associated with a convergence in water vapor over the YRV region due to the northward marching of EASM (Fig. 1a). The northward marching of EASM is characterized by a northward shift of positive anomalies of precipitation (Fig. 1b) and surface relative humidity (Fig. 1c) and negative anomalies of 500-hPa $\omega$ (Fig. 1d) from the southern part of East China during the early June toward the northern part of East China during the mid-July, which results in increased precipitation (Fig. 1b) and surface relative humidity (Fig. 1c) and enhanced convection (Fig. 1d) over the YRV region during mid-to-late June and early July. Particularly, most significant anomalies of precipitation, surface relative humidity, and 500-hPa $\omega$ occupy the YRV region around 25 June. The synoptic evolution in surface specific humidity is also examined (figure not shown). The results indicate that the specific humidity cannot well reflect the synoptic evolution of mei-yu in the YRV region, because the specific humidity over the YRV region continues increasing in July during and after the mei-yu period as the EASM marches northward over East Asia; meanwhile, the air temperature over the YRV region has an abrupt increase after late June and continues increasing in July, resulting in an abrupt increase in the saturation specific humidity after late June and a continuous increase in the saturation specific humidity in July over the YRV region. Thus, after late June, the air becomes less saturated with water vapor over the YRV region due to the significantly increased saturation specific humidity, which is closely related to the mei-yu decline, in spite of the increased specific humidity over the YRV region.

Hence, the synoptic evolution of mei-yu in the YRV region is generally characterized by an increase (decrease) 

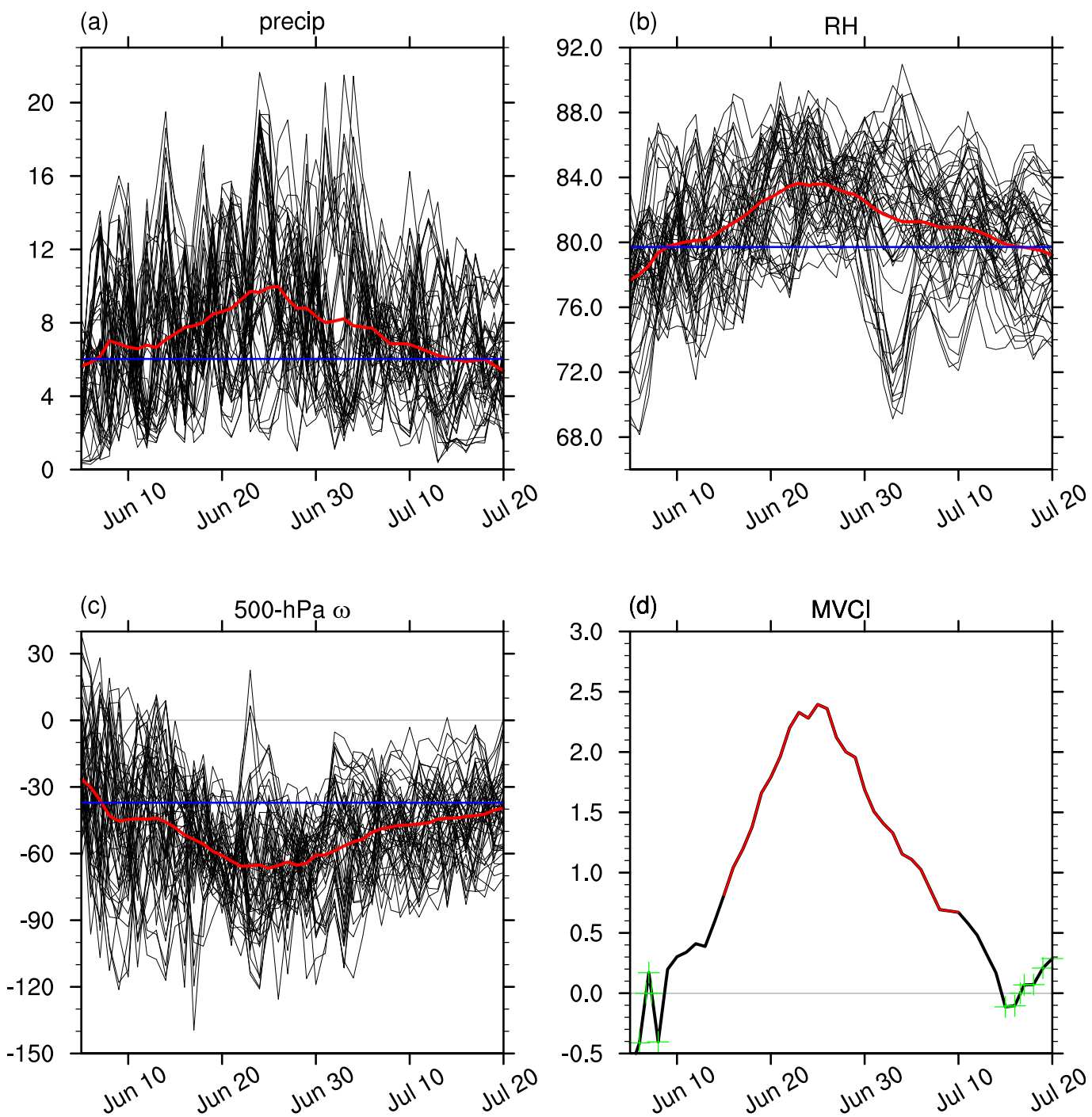

FIG. 2. Evolution of areal mean (a) precipitation (unit: $\mathrm{mm} \mathrm{day}^{-1}$ ), (b) surface relative humidity (unit: \%), and (c) 500-hPa $\omega$ (unit: $10^{-3} \mathrm{~Pa} \mathrm{~s}^{-1}$ ) over the YRV region during 6 Jun-20 Jul for 1961-2016. (d) Evolution of the corresponding MVCI (unit: 1) during 6 Jun-20 Jul for 1961-2016. Black lines in (a)-(c) represent individual years during 1961-2016. Red lines in (a)-(c) represent the average of individual years during 1961-2016. Blue lines in (a)-(c) represent the level of MJJA climatology. The MVCI in (d) is calculated based on the averaged synoptic evolution of precipitation, surface relative humidity, and 500-hPa $\omega$ during 1961-2016 [i.e., the red lines in (a)-(c)]. The red curve in (d) denotes where the anomalies of precipitation, surface relative humidity, and 500-hPa $\omega$ all exceed the levels of half standard deviation of the corresponding variables during summer; the green " + " markers in (d) denote where at least one of the anomalies of precipitation, surface relative humidity, and 500-hPa $\omega$ does not accord with the features of mei-yu.

in precipitation and surface relative humidity and a decrease (increase) in 500-hPa $\omega$ before (after) late June (Figs. 2a-c). This synoptic evolution of mei-yu may be specifically defined by several factors, including when the three indicators of mei-yu begin or stop significantly changing in the YRV region, when the anomalies of these three indicators reach a peak in the YRV region with respect to their normal levels during summer, and what are the maximum anomalies of these three indicators of mei-yu during this process. It is somewhat difficult to promptly and clearly obtain an understanding of the aforementioned factors based on the time series of precipitation, surface relative humidity, and 500-hPa $\omega$ (Figs. 2a-c). Thus, for a given period, an index (the MVCI) denoting the synoptic evolution of the anomalies in precipitation, surface relative humidity, and $500-\mathrm{hPa} \omega$ is defined based on a multivariable covariance (MVC) method: 


$$
\operatorname{MVCI}_{i}=\sqrt[3]{\frac{P_{i}^{\prime}}{\operatorname{sd}(p)} \times \frac{r_{i}^{\prime}}{\operatorname{sd}(r)} \times \frac{\omega_{i}^{\prime} \times(-1)}{\operatorname{sd}(\omega)}}
$$

where $p_{i}^{\prime}=p_{i}-\bar{p}, r_{i}^{\prime}=r_{i}-\bar{r}$, and $\omega_{i}^{\prime}=\omega_{i}-\bar{\omega}$. In the above formula, $p_{i}, r_{i}$, and $\omega_{i}$ are the areal mean precipitation, surface relative humidity, and 500-hPa $\omega$ over the YRV region on the $i$ th day during summer averaged for all individual years in the given period; $\bar{p}, \bar{r}$, and $\bar{\omega}$ are the summer climatology of areal mean precipitation, surface relative humidity, and 500-hPa $\omega$ over the YRV region for the reference period 1961-2016; $\operatorname{sd}(p), \operatorname{sd}(r)$, and $\operatorname{sd}(\omega)$ are the standard deviation of areal mean precipitation, surface relative humidity, and $500-\mathrm{hPa}$ $\omega$ over the YRV region during summer for the reference period 1961-2016. The MVCI synthesizes the information of precipitation, surface relative humidity, and $500-\mathrm{hPa} \omega$, which reflects the synoptic evolution of the concurrent anomalies in precipitation and surface relative humidity and 500-hPa $\omega$. The MVCI should be notably increased during the mei-yu period in the YRV region due to the large anomalies in the three indicators of mei-yu.

Correspondingly, Fig. 2d shows the synoptic evolution of MVCI during June and July for 1961-2016. The MVCI begins to notably increase in the mid-June, which reaches a peak on 25 June and decreases afterward toward the zero level in the mid-July. Particularly, the period where the anomalies of precipitation, surface relative humidity, and 500-hPa $\omega$ all accord with the mei-yu features and all exceed the levels of half standard deviation of corresponding variables during summer could be considered a significant mei-yu period, which spans from 15 June to 10 July (Fig. 2d). This result is basically consistent with the estimation of the mei-yu period (17 June8 July) for the YRV region by Ding et al. (2007).

The MVCI could be efficient for illustrating the synoptic features of mei-yu regarding the duration of mei-yu, the date of mei-yu peak (mei-yu peak refers to the maximum anomalies of mei-yu indicators during the mei-yu period), and the intensity of mei-yu. Specifically, the duration of mei-yu could be estimated based on the aforementioned threshold defined by the levels of half a standard deviation of the corresponding variables. The date of mei-yu peak could be defined by the date of MVCI reaching its peak. The intensity of mei-yu could be defined by the maximum value of MVCI during the meiyu period.

\section{$b$. Interdecadal variation in the synoptic-scale features of the MVCI}

To investigate the interdecadal variation in the synoptic features of mei-yu in the YRV region, the MVCI values for five running windows (9-, 11-, 13-, 15-, and 17-yr windows) from 1961 to 2016 are examined. The results for these running windows consistently indicate a noticeable interdecadal variation in the synoptic-scale features of the MVCI. Specifically, Fig. 3 shows the interdecadal variation in the date of the MVCI peak and the maximum value of the MVCI during June and July for the 11-, 13-, and 15-yr running windows. The date of the mei-yu peak (Figs. 3a,c,e) mostly occurred during 21-26 June before the mid-1980s. After the mid-1980s, the mei-yu peak was postponed to the early July. Later, in the late 1990s, the date of the mei-yu peak underwent another interdecadal change, which was advanced to an earlier date around 25 June in recent years.

Similarly, the maximum value of MVCI during June and July, which denotes the mei-yu intensity, underwent a noticeable increase after the mid-1980s (Figs. 3b,d,f). The maximum value of MVCI maintained a relatively high level through the 1990s and early 2000s and fell to a low level after the early 2000s. Note that the magnitudes of the maximum value of MVCI are slightly different for different running windows, because the synoptic evolution in MVCI is more (less) smooth for a larger (smaller) window and hence relatively small (large) maximum values of MVCI are observed for relatively large (small) windows (Figs. 3b,d,f). This property of the MVCI does not affect the feature of the interdecadal variation in the maximum value of the MVCI. The aforementioned interdecadal variation in the intensity of mei-yu is partially consistent with the interdecadal variation in the date of mei-yu peak regarding the interdecadal change occurring in the mid-1980s, implying that the interdecadal changes in the date of mei-yu peak and in the intensity of mei-yu might be associated with the same factor. On the other hand, an inconsistency is observed between the interdecadal change in the date of the mei-yu peak occurring in the mid-1990s and the interdecadal change in the mei-yu intensity occurring in the early 2000s. overall, the above results suggest distinct synoptic features of mei-yu during the period before the mid-1980s, the period from the mid-1980s to the $1990 \mathrm{~s}$, and the period after the early 2000 s.

Hence, the mechanisms associated with the synoptic features of mei-yu are examined for three specific periods in the following sections: 1961-80, 1985-97, and 2006-16. The synoptic features of mei-yu during 1961-80 and 2006-16 are characterized by a relatively early date of mei-yu peak and a relatively small intensity of mei-yu, whereas the synoptic features of mei-yu during 1985-97 are characterized by a relatively late date of mei-yu peak and a relatively large intensity of mei-yu (Fig. 3). Based on the MVCI for 1961-80, 1985-97, and 2006-16, the dates of mei-yu 

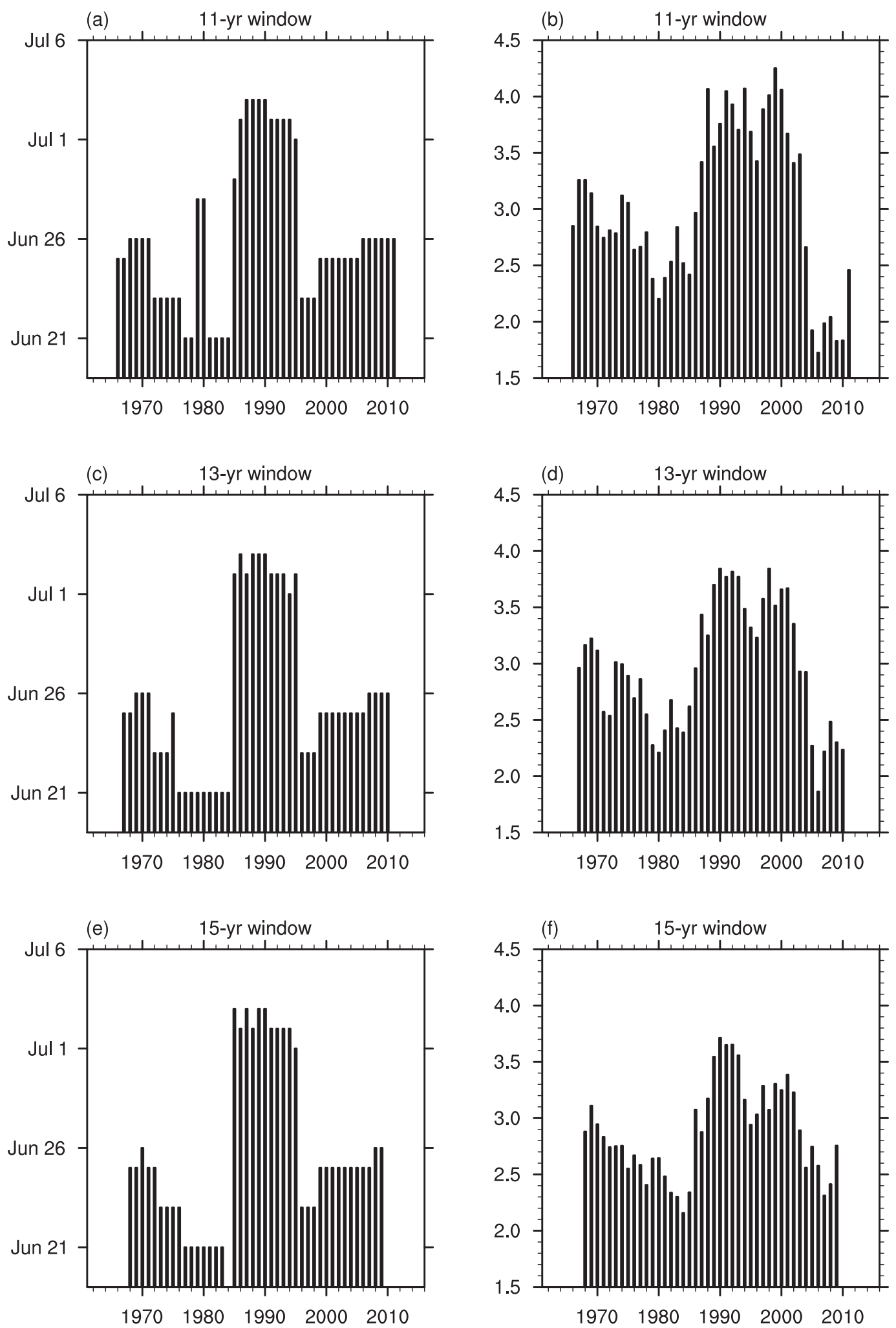

FIG. 3. Interdecadal variation of the (a),(c),(e) date of maximum MVCI and (b),(d),(f) maximum value of MVCI (unit: 1) during June-July based on MVCIs for an (a),(b) 11-yr, (c),(d) 13-yr, and (e),(f) 15-yr running window during 1961-2016. 

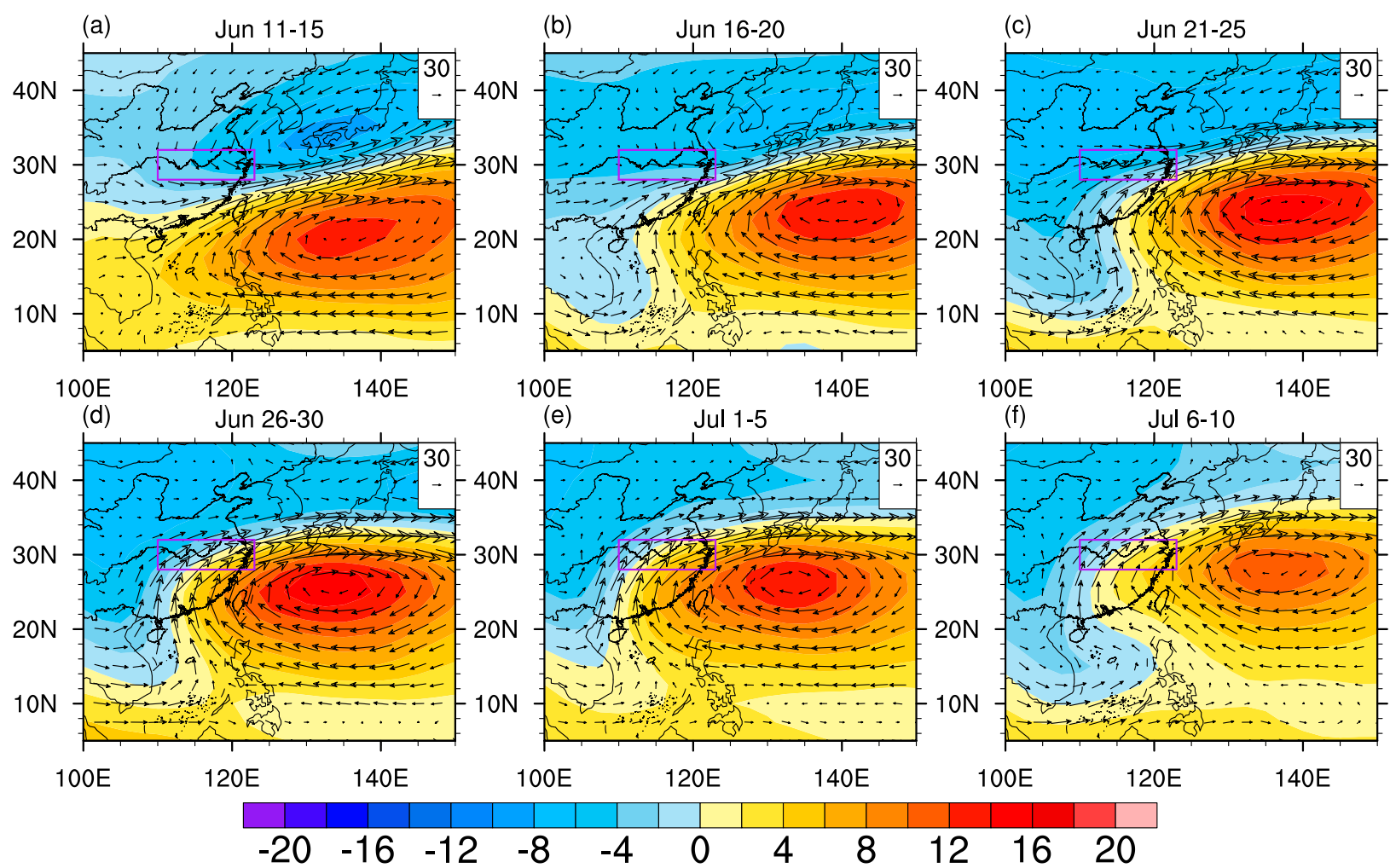

FIG. 4. Evolution of pentad mean anomalies of vertically integrated WVT (vector; unit: $\mathrm{kg} \mathrm{m}^{-1} \mathrm{~s}^{-1}$ ) with respect to MJJA climatology and the corresponding streamfunction (shading; unit: $10^{7} \mathrm{~kg} \mathrm{~s}^{-1}$ ) during $11 \mathrm{Jun}-10 \mathrm{Jul}$ for 1961-2016.

peak during the three periods are respectively 25 June, 2 July, and 26 June.

\section{Mechanisms of the interdecadal variation in the date of mei-yu peak}

\section{a. Synoptic evolution of water vapor transport}

The mei-yu peak denotes the most significant anomalies in precipitation, surface relative humidity, and vertical motion over the YRV region during June and July, which are associated with strongly converged WVT and enhanced convection over the YRV region. Figure 4 shows the evolution of pentad mean anomalies of the vertically integrated WVT with respect to summer climatology during 11 June-10 July for 1961-2016. It can be seen that an anomalous anticyclone shifts northwestward over the western North Pacific (WNP) during mid- and late June (Figs. 4a-d). The southerly WVT anomalies along the western flank of this anomalous anticyclone cause increased meridional WVT over southeastern China $\left(20^{\circ}-30^{\circ} \mathrm{N}, 110^{\circ}-123^{\circ} \mathrm{E}\right)$ and anomalous convergence of water vapor over the YRV region in late June (Figs. 4c,d). The significantly increased meridional WVT and strong convergence of water vapor over the YRV region could induce significant anomalies of precipitation and surface relative humidity, which are important reasons for the occurrence of mei-yu peak. Thus, the variability in the date of mei-yu peak is closely connected with the synoptic evolution of the meridional WVT anomalies over southeastern China, which flow along the western flank of the anomalous anticyclone over the WNP during June and July.

The above results (Fig. 4) suggest an important role of the synoptic evolution of meridional WVT over southeastern China $\left(20^{\circ}-30^{\circ} \mathrm{N}, 110^{\circ}-123^{\circ} \mathrm{E}\right)$ in inducing an increased water vapor convergence over the YRV region $\left(28^{\circ}-32^{\circ} \mathrm{N}, 110^{\circ}-123^{\circ} \mathrm{E}\right)$ during late June. To illustrate the interdecadal variation in the synoptic evolution of meridional WVT (hereafter referred as $v q$ ) over the WNP and southeastern China during the mei-yu period, Figs. 5a-c show the time-longitude section of $v q$ anomalies averaged within $20^{\circ}-30^{\circ} \mathrm{N}$ and Figs. $5 \mathrm{~d}-\mathrm{f}$ show the time-latitude section of $v q$ anomalies averaged within $110^{\circ}-123^{\circ} \mathrm{E}$ for the three target periods (i.e., 1961-80, 1985-97, and 2006-16). As shown in Figs. 5a-c, the westward shift of positive $v q$ anomalies during 11 June-11 July exhibited a delay for 1985-97 in comparison to the other two periods, where significant positive $v q$ anomalies occurred in southeastern China 

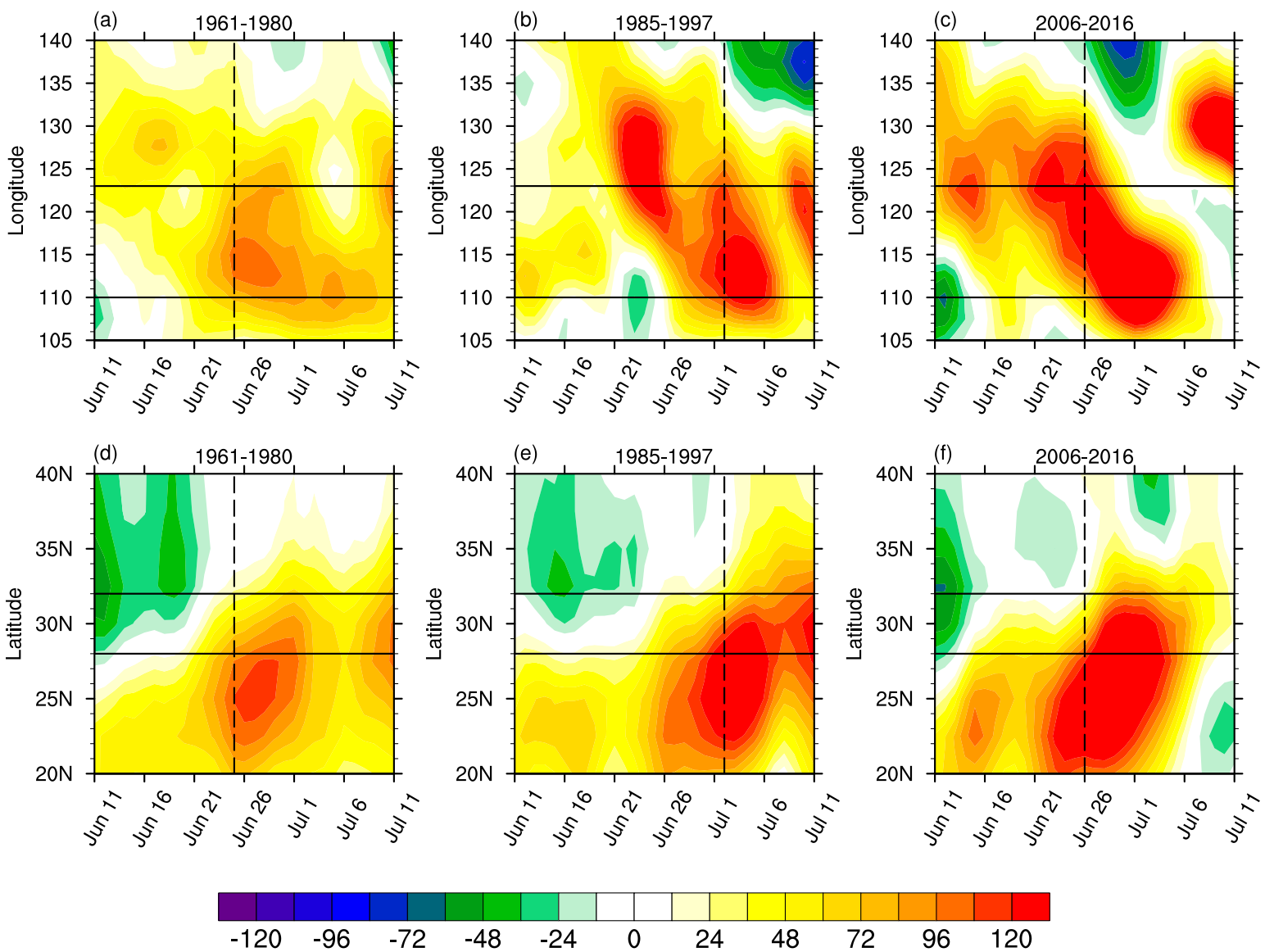

(g)

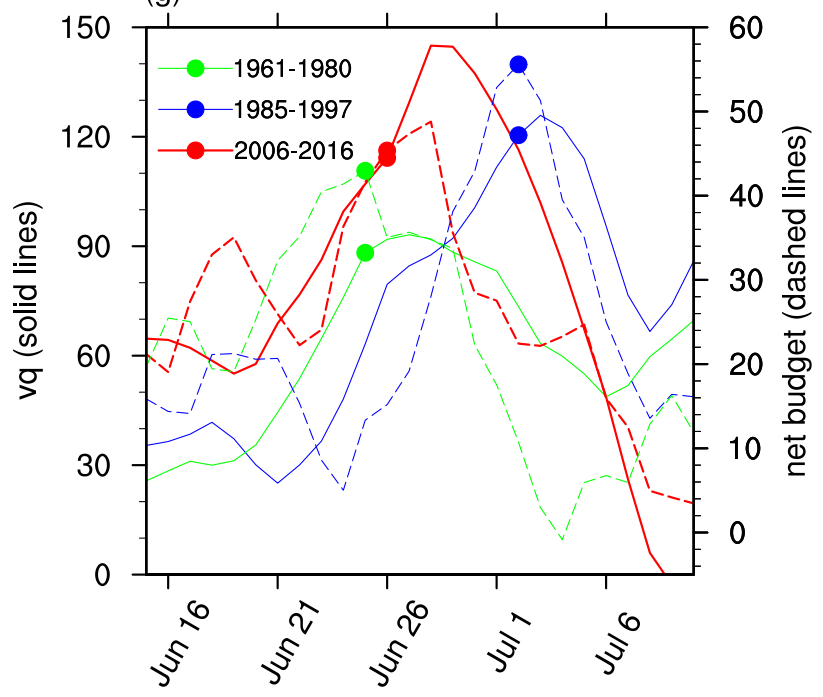

FIG. 5. Time-longitude section of (a)-(c) meridional WVT anomalies averaged within $20^{\circ}-30^{\circ} \mathrm{N}$ and time-latitude section of (d)-(f) meridional WVT anomalies averaged within $110^{\circ}-123^{\circ} \mathrm{E}$ during $11 \mathrm{Jun}-11 \mathrm{Jul}$ for (a),(d) 1961-80, (b),(e) 1985-97, and (c),(f) 2006-16 (unit: $\mathrm{kg} \mathrm{m}^{-1} \mathrm{~s}^{-1}$ ) with respect to MJJA climatology. (g) Evolution of the anomalies of meridional WVT (solid lines; unit: $\mathrm{kg} \mathrm{m}^{-1} \mathrm{~s}^{-1}$ ) averaged over southeastern China $\left(20^{\circ}-30^{\circ} \mathrm{N}, 110^{\circ}-123^{\circ} \mathrm{E}\right)$ and the anomalies of net water vapor flux (dashed lines; unit: $\left.10^{6} \mathrm{~kg} \mathrm{~s}{ }^{-1}\right)$ over the YRV region during 15 Jun-10 Jul for 1961-80 (in green), 1985-97 (in blue), and 2006-16 (in red) with respect to MJJA climatology. The horizontal solid lines in (a)-(c) represent the longitudinal range of the YRV region $\left(110^{\circ}-123^{\circ} \mathrm{E}\right)$. The horizontal solid lines in (d)-(f) represent the latitudinal range of the YRV region $\left(28^{\circ}-32^{\circ} \mathrm{N}\right)$. The vertical dashed lines in (a)-(f) denote the days of mei-yu peak. The dots in (g) denote the days of mei-yu peak for the three periods. The left and right $y$ axes in $(\mathrm{g})$ are for the solid and dashed lines, respectively. 
$\left(110^{\circ}-123^{\circ} \mathrm{E}\right)$ in early July (late June) during $1985-97$ (1961-80 and 2006-16). Similarly, as shown in Figs. 5d-f, the northward march of positive $v q$ anomalies over southeastern China during 11 June-11 July also exhibited a delay for 1985-97 in comparison to the other two periods, where the positive $v q$ anomalies largely marched into the region north of $32^{\circ} \mathrm{N}$ after 2 July (25/ 26 June) during 1985-97 (1961-80 and 2006-16).

Correspondingly, Fig. $5 \mathrm{~g}$ shows the synoptic evolution of $v q$ anomalies averaged over southeastern China $\left(20^{\circ}-\right.$ $30^{\circ} \mathrm{N}, 110^{\circ}-123^{\circ} \mathrm{E}$ ) during 15 June- 10 July for the three periods. It can be seen that the evolution of $v q$ anomaly for 1985-97 lagged the evolution of $v q$ anomalies for 1961-80 and 2006-16. The $v q$ anomaly increased in the late June and reached its peak on 27 and 28 June during 1961-80 and 2006-16, respectively; in contrast, the $v q$ anomaly reached its peak on 3 July during 1985-97. The delayed increase of $v q$ anomaly over southeastern China in late June during 1985-97 induced a delayed increase of net water vapor flux over the YRV region $\left(28^{\circ}-32^{\circ} \mathrm{N}\right.$, $110^{\circ}-123^{\circ} \mathrm{E}$ ) in late June (Fig. $5 \mathrm{~g}$ ), resulting in a delayed mei-yu peak. Note that although the $v q$ anomaly over southeastern China during the mei-yu period is smaller for 1985-97 than for 2006-16 (Fig. 5g), the anomaly of net water vapor flux over the YRV region during the mei-yu period is larger for 1985-97 than for 2006-16 (Fig. 5g), which is consistent with the relatively large (small) intensity of mei-yu during 1985-97 (2006-16) (Fig. 3). The above results suggest an impact of a delayed enhancement of the southerly WVT anomalies over southeastern China in the late June on the delayed mei-yu peak during 1985-97.

\section{b. Relationship with PDO}

A question then arises: What caused the delayed enhancement of the southerly WVT anomalies over southeastern China in the late June during 1985-97? Essentially, the enhancement of the southerly WVT anomalies over southeastern China is induced by the northwestward extension of the anomalous anticyclone over the WNP in late June (Fig. 4). The northwestward extension of the anomalous anticyclone over the WNP reflects the westward extension and northward shift of the western Pacific subtropical high (WPSH) in June (Si et al. 2008; Yang et al. 2017). The interdecadal variation in the WPSH could exert an important impact on the northwestward extension of the anomalous anticyclone over the WNP during June. However, the interdecadal variation of WPSH over past decades remains controversial, because the 500-hPa geopotential height experienced notable changes around the globe due to the global warming over past decades, which makes the reasonableness of the conventional metrics for WPSH based on $500-\mathrm{hPa}$ geopotential height debatable (Lu et al. 2008; Zhou et al. 2009; He et al. 2015; Huang and Li 2015; Y. Huang et al. 2015).

One of the most significant characteristics of the subtropical high over the North Pacific is the clockwise gyre pattern in the wind field and the WVT field over the North Pacific (Fig. 6a). The interdecadal variation in the pattern of WVT over the North Pacific and East Asia is examined to inspect the mechanism underlying the interdecadal variation in the northwestward extension of the anomalous anticyclone over the WNP. Figure $6 \mathrm{~b}$ shows the differences in MJJA mean WVT between 1985-97 and 1961-80. The northerly WVT anomalies over the WNP, the southerly WVT anomalies over the eastern North Pacific, the westerly WVT anomalies over the low-latitudinal North Pacific, and the easterly WVT anomalies over the high-latitudinal North Pacific manifest an anticlockwise gyre pattern over the North Pacific, suggesting that the climatic clockwise WVT over the North Pacific associated with the subtropical high was weakened during the summer of 1985-97. This anomalous anticlockwise gyre was particularly characterized by northerly WVT anomalies over the WNP and eastern China (Fig. 6b). These northerly WVT anomalies in the background circulation during summer provided an unfavorable climatic condition for the southerly WVT anomalies along the western flank of the anomalous anticyclone over the WNP in late June. Climatically, during late June, the edge of the anomalous anticyclone over the WNP, which is denoted by the zero line of the streamfunction of WVT anomalies (Fig. 7a), moves northwestward gradually, resulting in southerly WVT anomalies reaching the YRV region along the western flank of the anomalous anticyclone. During 1985-97, the northerly WVT anomalies over the WNP and eastern China in the background circulation during summer (Fig. 6b) may induce weakened southerly WVT anomalies along the western flank of the anomalous anticyclone over the WNP in the late June (Fig. 7d), which impeded the northwestward extension of the edge of the anomalous anticyclone over the WNP in late June (Figs. 7e,f). Accordingly, the southerly WVT anomalies along the western edge of the anomalous anticyclone reached the YRV region late, contributing to a delayed mei-yu peak during 1985-97.

On the contrary, Fig. $6 \mathrm{c}$ shows the differences in MJJA mean WVT between 2006-16 and 1985-97, which exhibit a clockwise gyre pattern of WVT anomalies over the North Pacific, suggesting that the climatic clockwise WVT over the North Pacific associated with the subtropical high was enhanced during the summer of 2006-16 in comparison to 1985-97. Accordingly, the southerly WVT anomalies over the WNP and eastern China in the background 


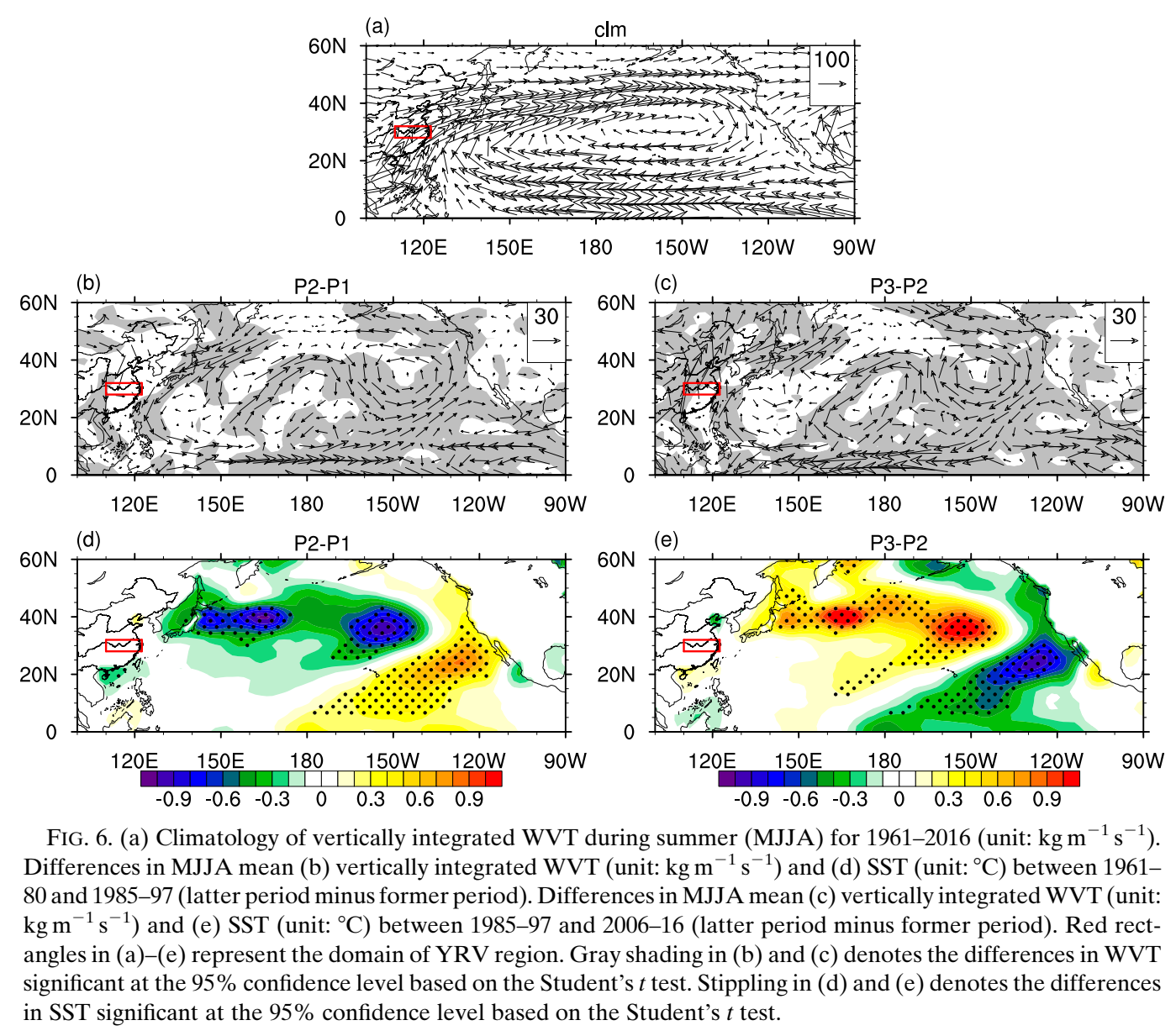

circulation during summer (Fig. 6c) provided a favorable climatic condition for the southerly WVT anomalies along the western flank of the anomalous anticyclone over the WNP in the late June (Figs. 7g-i), contributing to a relatively early mei-yu peak during 2006-16.

The aforementioned interdecadal changes in the WVT over the North Pacific correspond to significant interdecadal changes in the SSTs over the North Pacific, which present patterns resembling the PDO mode (Mantua and Hare 2002) (Figs. 6d,e). As shown in Fig. 6d, the differences in summer SST between 198597 and 1961-80 are characterized by negative anomalies in the midlatitudinal North Pacific and positive anomalies in the low-latitudinal eastern Pacific, suggesting a positive phase of the PDO during 1985-97. Conversely, the differences in summer SST between 2006-16 and 1985-97 suggest a negative phase of the PDO during 2006-16 (Fig. 6e). The above results imply an influence of PDO on the interdecadal variation in the clockwise gyre over the North Pacific, which may play a role in the interdecadal variation of the timing of mei-yu peak over the YRV region.
During the past several decades, the PDO underwent an interdecadal variation characterized by a negative phase during the 1960s and 1970s, a positive phase during the 1980s and 1990s, and a largely negative phase during the 2000s and 2010s (Fig. 8a). To examine the climate anomalies associated with the PDO, Figs. $8 \mathrm{~b}$ and $8 \mathrm{c}$ show the anomalies of SST and WVT, respectively, regressed on the 5-yr running mean time series of the MJJA mean PDO index during 1961-2016. The SST anomalies corresponding to a positive phase of the PDO are mainly characterized by negative anomalies in the midlatitudinal North Pacific and positive anomalies in the low-latitudinal eastern Pacific (Fig. 8b). The associated WVT anomalies are characterized by an anticlockwise gyre pattern over the North Pacific (Fig. 8c). Particularly, northerly WVT anomalies over the WNP and eastern China are detected to be associated with a positive phase of the PDO (Fig. 8c). These northerly WVT anomalies in the background circulation during summer may provide an unfavorable climatic condition for the southerly WVT anomalies along the western flank of the anomalous anticyclone over the WNP in the 

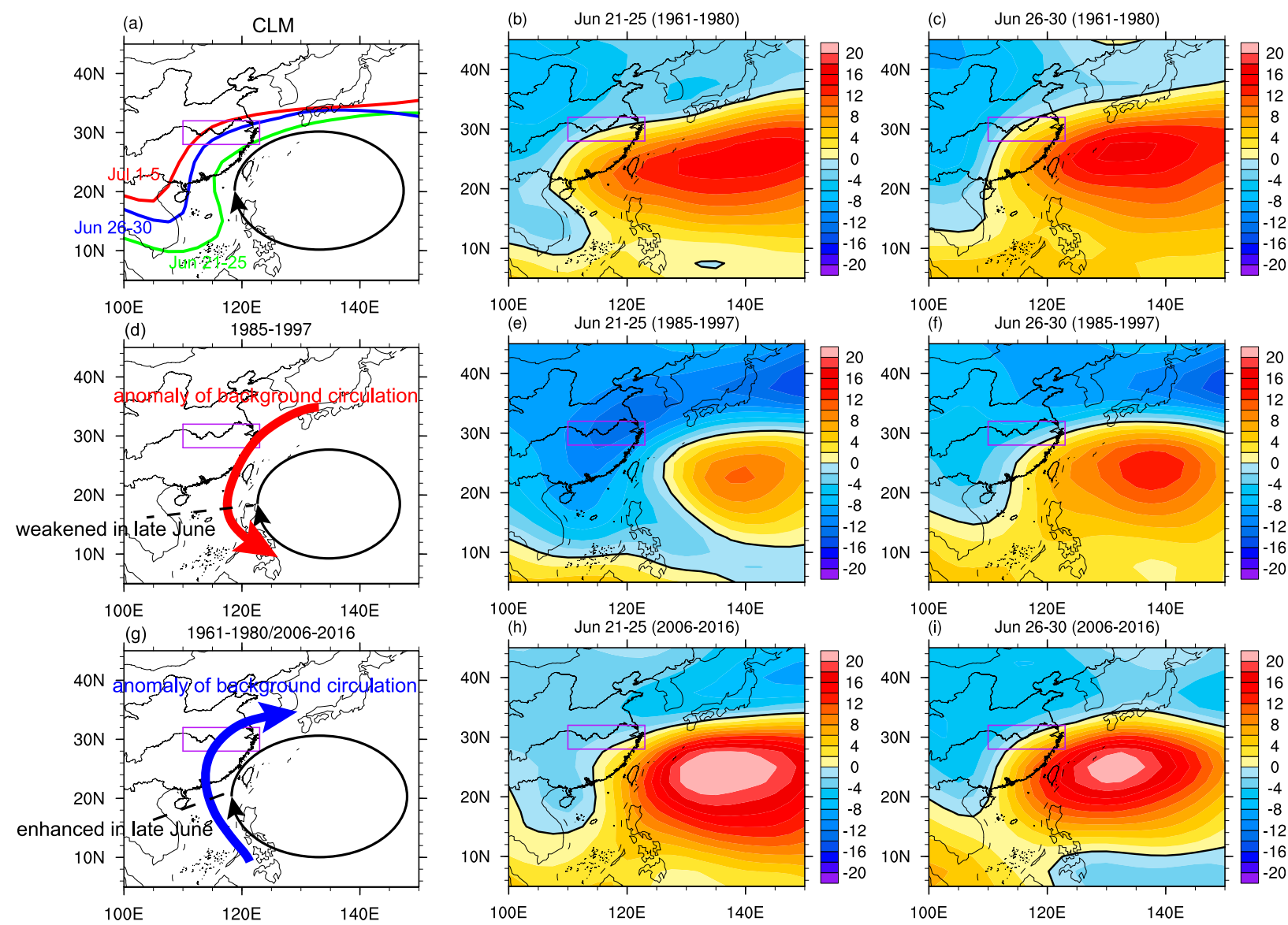

FIG. 7. (a) Climatic locations of the zero line of streamfunction of WVT anomalies during 21-25 Jun (in green), 26-30 Jun (in blue), and 1-5 Jul (in red) with respect to MJJA climatology. Streamfunction (unit: $10^{7} \mathrm{~kg} \mathrm{~s}^{-1}$ ) of WVT anomalies during (b),(e),(h) 21-25 Jun and (c),(f),(i) 26-30 Jun with respect to MJJA climatology for (b),(c) 1961-80, (e),(f) 1985-97, and (h),(i) 2006-16, with the thick black contour lines denoting the zero lines. Schematic diagrams for the interaction between the anomaly of background circulation during summer and the anomalous anticyclone over the WNP in the late June during (d) 1985-97 and during (g) 1961-80 and 2006-16. The black circle in (a), (d), and (g) denotes the anomalous anticyclone over the WNP in the late June. The red arrow in (d) denotes the anomaly of background circulation in the summer during 1985-97; the blue arrow in $(\mathrm{g})$ denotes the anomaly of background circulation in the summer during 1961-80 and 2006-16. Purple rectangles in (a)-(i) represent the domain of YRV region.

late June (Fig. 7d) and lead to a delayed mei-yu peak in the YRV region. Hence, the positive phase of the PDO may be a factor contributing to the delayed mei-yu peak during 1985-97. Based on observation and numerical experiments, Zhu et al. (2011, 2015) suggested that the SST anomalies associated with a positive phase of the PDO may stimulate a weakened WPSH during summer, which may result in an anomalous anticlockwise gyre pattern of WVT over the North Pacific. This result is consistent with the above results of this study.

\section{Mechanisms of the interdecadal variation in mei-yu intensity}

The relatively large (small) intensity of mei-yu during 1985-97 (1961-80 and 2006-16) is associated with an interdecadal variation in the precipitation, surface relative humidity, and vertical motion over the YRV region during the mei-yu period. Figure 9 shows the 11-yr running mean time series of areal mean precipitation, relative humidity, and 500-hPa $\omega$ over the YRV region during the mei-yu period (15 June-10 July) for the past several decades. The precipitation during the mei-yu period was notably increased after the mid-1980s and fell toward a low level during the recent years after the early 2000s (Fig. 9a). The interdecadal variation in the tropospheric vertical motion during the mei-yu period is largely consistent with precipitation, featuring an enhanced ascending motion over the YRV region from the mid-1980s to the early 2000s and a reduced ascending motion over the YRV region after the early 2000s (Fig. 9c). In contrast, the surface relative humidity during 

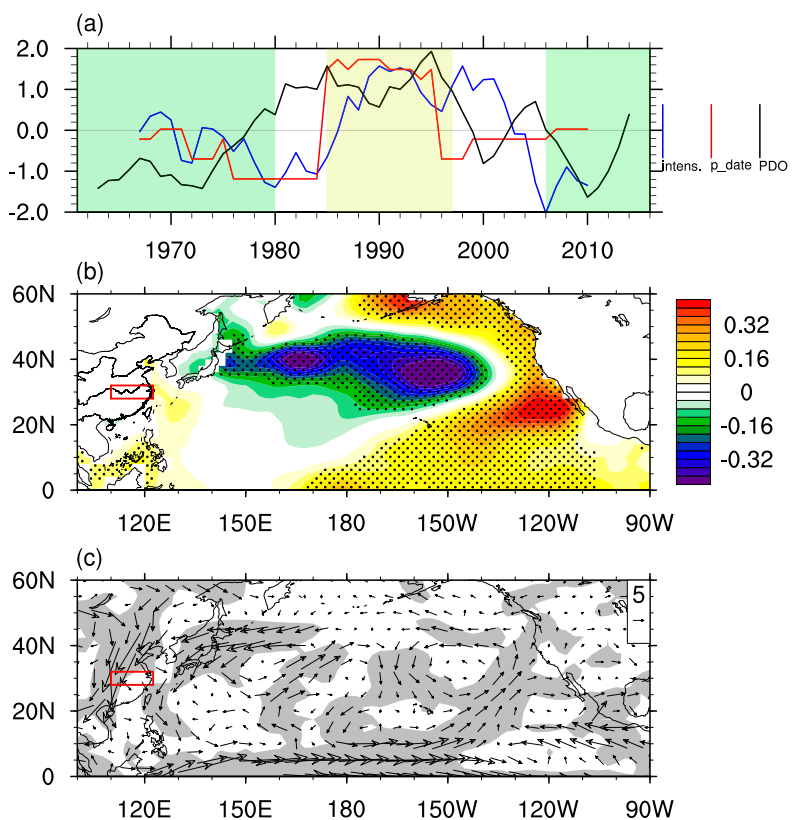

FIG. 8. (a) Standardized 5-yr running mean time series of MJJA PDO index (in black) and standardized time series of mei-yu intensity (in blue) and date of mei-yu peak (in red) based on MVCIs for a 13-yr running window during 1961-2016. Anomalies of MJJA mean (b) SST (unit: ${ }^{\circ} \mathrm{C}$ ) and (c) vertically integrated WVT (unit: $\mathrm{kg} \mathrm{m}^{-1} \mathrm{~s}^{-1}$ ) regressed on standardized 5-yr running mean time series of MJJA PDO index. The green shading in (a) denotes the time span of 1961-80 and 2006-16; the yellow shading in (a) denotes the time span of 1985-97. Red rectangles in (b) and (c) represent the domain of YRV region. Stippling in (b) and gray shading in (c) denote where the anomalies of SST and WVT are significant at the 95\% confidence level based on a Monte Carlo test, respectively.

the mei-yu period did not undergo an interdecadal change in the mid-1980s, but fell rapidly toward a low level after the 1990s (Fig. 9b), exhibiting an interdecadal variation different from that of precipitation and tropospheric vertical motion. Specifically, a significant correlation is detected between the time series of precipitation and 500-hPa $\omega$ with a correlation coefficient of -0.74 (Figs. 9a,c), whereas a smaller correlation coefficient is detected between the time series of precipitation and surface relative humidity with a value of 0.36 (Figs. 9a,b). These results suggest that the dynamical processes associated with the tropospheric vertical motion over the YRV region exerted an important impact on the interdecadal variation of precipitation during the mei-yu period during past decades, which are consistent with the study by Wang and Paegle (1996) indicating that the variability of regional moisture flux and moisture budget is more sensitive to dynamic process than moisture distribution.

Actually, the aforementioned interdecadal variation in precipitation, tropospheric vertical motion, and surface
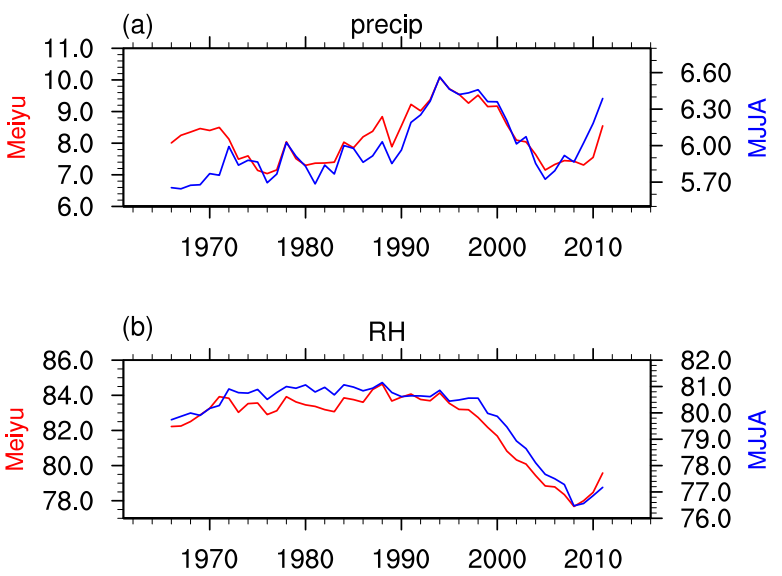

(c)

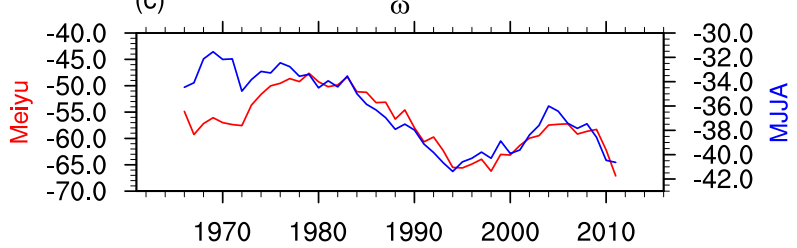

(d)

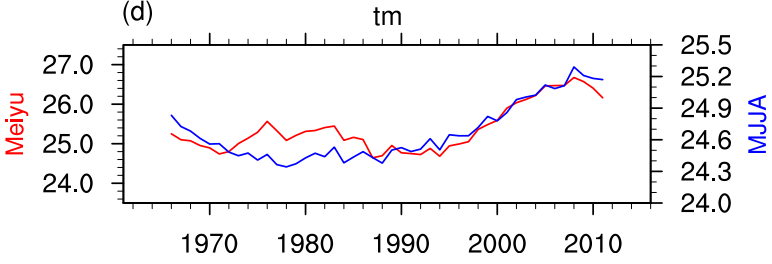

FIG. 9. 11-yr running mean time series of daily mean (a) precipitation (unit: $\mathrm{mm} \mathrm{day}^{-1}$ ), (b) surface relative humidity (unit: \%), (c) 500-hPa $\omega$ (unit: $10^{-3} \mathrm{~Pa} \mathrm{~s}^{-1}$ ), and (d) surface temperature (unit: ${ }^{\circ} \mathrm{C}$ ) averaged over the YRV region during the mei-yu period (16 Jun$6 \mathrm{Jul}$ ) (in red) and during MJJA (in blue). The left and right $y$ axes are for the red and blue lines, respectively.

relative humidity during the mei-yu period is largely consistent with the interdecadal variation in MJJA mean precipitation, tropospheric vertical motion, and surface relative humidity over the YRV region, regarding the increased (decreased) precipitation and enhanced (weakened) ascending motion over the YRV region after the mid-1980s (early 2000s) as well as the rapidly decreased surface relative humidity over the YRV region after the 1990s (Fig. 9). Thus, the mechanisms of the interdecadal variation of mei-yu intensity could be inferred from the mechanisms of the interdecadal variation of summer climate over the YRV region.

\section{a. Interdecadal variation of the large-scale tropical east-west circulation}

Zhu et al. $(2011,2015)$ have suggested that the PDO plays an important role for the interdecadal change of 


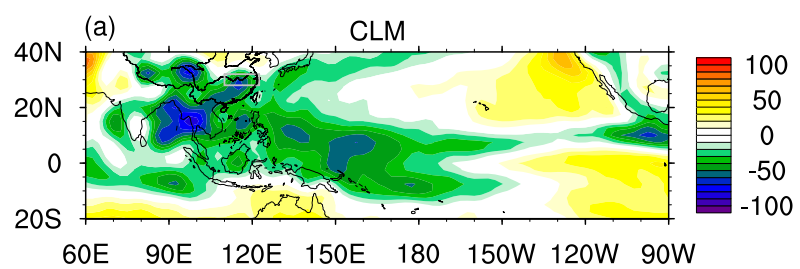

(b) P2-P1
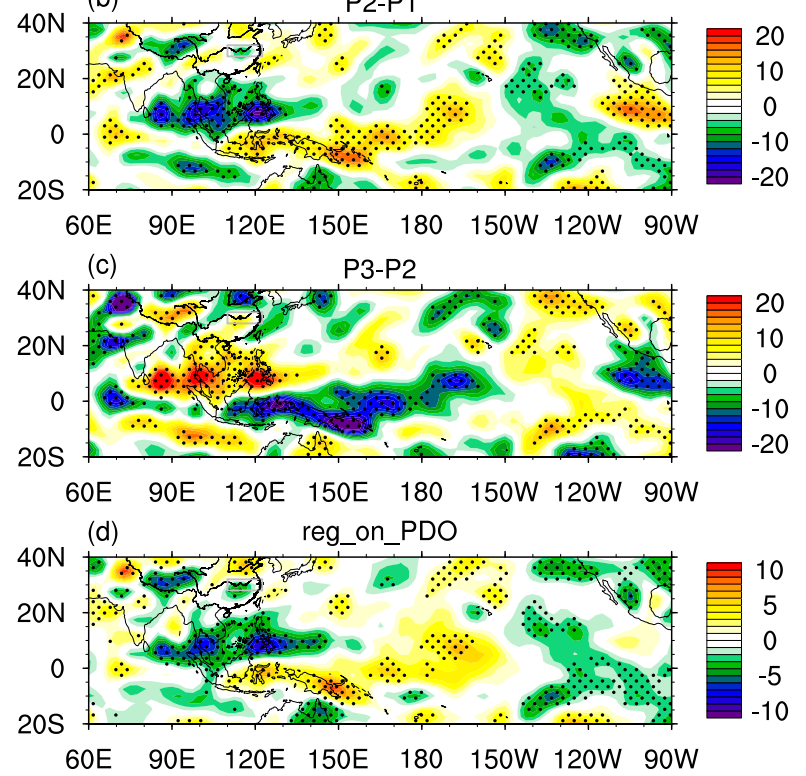

FIG. 10. (a) Climatology of MJJA 500-hPa $\omega$ during 1961-2016. (b) Differences in 500-hPa $\omega$ between 1961-80 and 1985-97 (latter period minus former period). (c) Differences in 500-hPa $\omega$ between 1985-97 and 2006-16 (latter period minus former period). (d) Anomalies of 500-hPa $\omega$ regressed on standardized 5-yr running mean time series of MJJA PDO index. Gray rectangles in (a)-(d) represent the domain of YRV region. Stippling in (b)-(d) denotes where the anomalies are significant at the $95 \%$ confidence level, where the significance test in (b) and (c) uses the Student's $t$ test and the significance test in (d) uses a Monte Carlo test. Unit: $10^{-3} \mathrm{~Pa} \mathrm{~s}^{-1}$.

summer climate over the YRV region after the late 1990s. It is proposed that the East Asian westerly jet stream weakens and shifts poleward during the summer in a negative phase of the PDO, which could cause anomalous tropospheric vertical motion over the YRV region and HRV region via an anomalous jet-related secondary meridional-vertical circulation (Zhu et al. 2015). Here, we propose another perspective on the association between the PDO and the vertical motion over the YRV region during summer, based on the effects of PDO on a large-scale tropical east-west circulation during summer (Krishnamurti 1971). As shown in Fig. 10a, during summer the ascending branches over a wide area that covers the western tropical Pacific, the Maritime Continent, and southern China and the descending branches over the eastern tropical Pacific together constitute a large-scale tropical east-west circulation, which contains the Walker circulation and Asian monsoon circulation (Krishnamurti 1971; Goswami et al. 1999; Tokinaga et al. 2012; McGregor et al. 2014).

The large-scale tropical east-west circulation underwent significant interdecadal variations over past decades. Figure $10 \mathrm{~b}$ shows the differences in MJJA mean 500-hPa $\omega$ between 1985-97 and 1961-80. It indicates that during 1985-97, the ascending branches over the northern Maritime Continent, the Indochina Peninsula, the YRV region, and the Tibetan Plateau were enhanced during summer in comparison to 1961-80, whereas descending (ascending) anomalies occurred in the troposphere over the southern Maritime Continent and western and central tropical Pacific (eastern tropical Pacific). The aforementioned enhanced ascending branch over the YRV region may result in an enhanced convection and hence an intensified mei-yu over the YRV region during summer. A converse interdecadal change occurred during 2006-16 (Fig. 10c). These interdecadal variations in the large-scale tropical east-west circulation are associated with interdecadal variations in the eastern tropical Pacific SSTs (Figs. 6d,e). It should be noted that although the PDO is generally considered a mode in the North Pacific basin, the SST anomalies associated with PDO are significant in the tropical Pacific, exhibiting an ENSO-like pattern (Fig. 8b; Mantua and Hare 2002). Corresponding to a positive phase of the PDO, the positive SST anomalies in the eastern tropical Pacific (Fig. 8b) may induce ascending anomalies in the troposphere over the eastern tropical Pacific, which may weaken the Walker circulation and hence induce descending anomalies over the western and central tropical Pacific and southern Maritime Continent (Fig. 10d). Furthermore, ascending anomalies may thus be enhanced in the troposphere over the area covering the northern Maritime Continent, the Indochina Peninsula, the YRV region, and the Tibetan Plateau to compensate for the descending anomalies over the southern Maritime Continent and western tropical Pacific (Fig. 10d), a process that resembles the East Asia-Pacific (EAP)/PacificJapan (PJ) teleconnection (Nitta 1987; Huang 1992).

In addition, an EOF analysis was performed for the $500-\mathrm{hPa} \omega$ within $60^{\circ} \mathrm{E}-90^{\circ} \mathrm{W}$ and $20^{\circ} \mathrm{S}-40^{\circ} \mathrm{N}$ to examine the dominant mode (EOF1) of the interdecadal variability of tropical vertical motions (Figs. 11a,b). The result indicates that the dominant mode of the interdecadal variability of tropical vertical motions (Fig. 11a) can largely account for the interdecadal variations of the large-scale tropical east-west circulation over past decades (Figs. 10b,c), which resemble the anomalies of 500-hPa $\omega$ associated with PDO (Fig. 10d). Correspondingly, the time series of the EOF1 exhibit a positive phase of this dominant mode in the 1980s and 1990s and a negative phase before the mid-1970s and after the 1990s, 

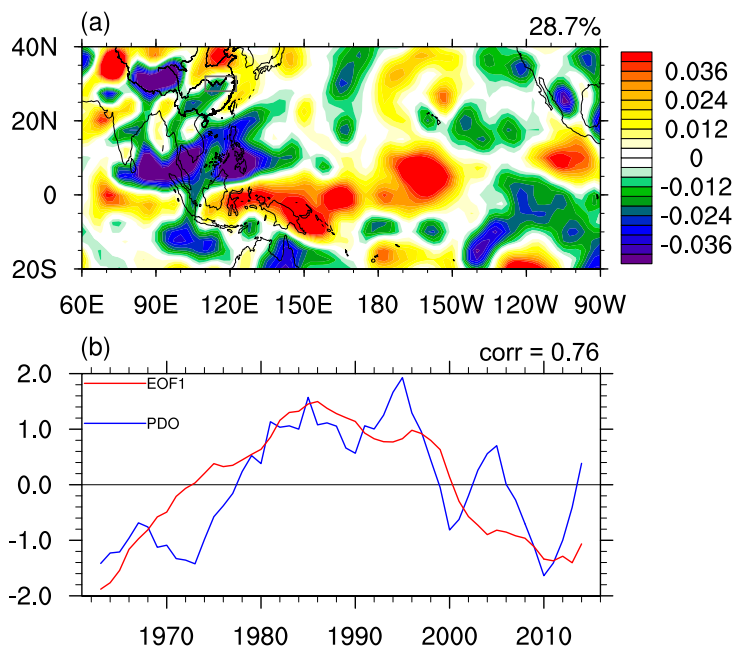

(c)

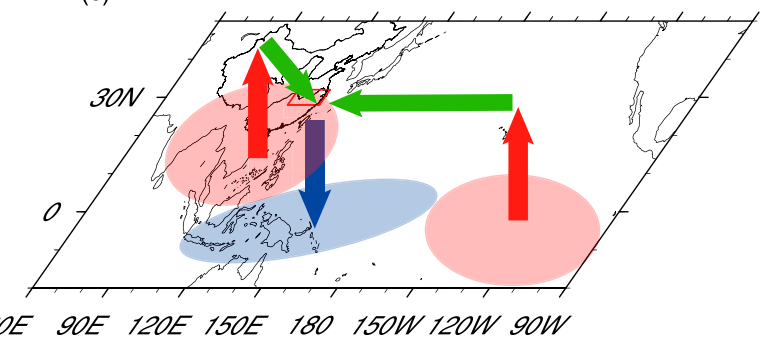

FIG. 11. (a) Leading EOF mode of the 5-yr running mean MJJA $500-\mathrm{hPa} \omega$ within $20^{\circ} \mathrm{S}-40^{\circ} \mathrm{N}$ and $60^{\circ} \mathrm{E}-90^{\circ} \mathrm{W}$, with the explained variance labeled in the top-right corner. (b) Standardized time series of the leading EOF mode in (a) (in red) and 5-yr running mean MJJA PDO index (in blue), with the correlation coefficient labeled in the top-right corner. (c) Schematic diagram for the anomalies of the large-scale tropical east-west circulation during summer in a positive phase of the PDO.

which are mostly consistent with the interdecadal oscillation of PDO (Fig. 11b). The time series of the EOF1 of interdecadal variability of tropical vertical motions and the time series of PDO index have a correlation coefficient of 0.76 , significant at the $95 \%$ confidence level (Fig. 11b). The above results suggest an influence of the tropical SST anomalies associated with PDO on the interdecadal variation of the large-scale tropical east-west circulation, which influenced the interdecadal variation of the vertical motion over the YRV region and hence the mei-yu intensity during summer. Figure $11 \mathrm{c}$ provides a schematic diagram for the modulation of the large-scale tropical east-west circulation corresponding to a positive phase of the PDO.

\section{b. Interdecadal variation of the water vapor flux budget and relative humidity}

The aforementioned interdecadal variation of vertical motion in the troposphere over the YRV region was accompanied by an interdecadal variation of water vapor flux budget over the YRV region during summer (Fig. 12). Considering that the water vapor is largely distributed in the lower troposphere and that an enhanced (weakened) convection is generally associated with an increased (decreased) convergence in the lower troposphere, an increased convergence in the vertically integrated WVT occurred over the YRV region in the summer during 1985-97 in comparison to 1961-80 (Fig. 12a), and a decreased convergence in the vertically integrated WVT occurred over the YRV region in the summer during 2006-16 in comparison to 1985-97 (Fig. 12b). Correspondingly, the interdecadal variation of net water vapor flux over the YRV region is characterized by an increased net water vapor flux during the 1980s and 1990s and a decreased net water vapor flux after the 1990s (Fig. 12c). This interdecadal variation in the water vapor flux budget over the YRV region during summer is largely consistent with the interdecadal variation in the precipitation over the YRV region during summer and during the mei-yu period (Fig. 12c), suggesting an important role of the water vapor flux budget over the YRV region in modulating the interdecadal variability of mei-yu intensity.

In addition, Figs. 13a and 13b show the differences in surface relative humidity during summer among the three periods. The difference in surface relative humidity between 1985-97 and 1961-80 is mostly insignificant over the YRV region (Fig. 13a). In contrast, the surface relative humidity was significantly decreased over the YRV region during 2006-16 in comparison to during 1985-97 (Fig. 13b). This interdecadal decrease in surface relative humidity is mainly attributed to an increased saturation specific humidity over the YRV region during 2006-16 (Fig. 13f). As shown in Fig. 13d, the surface air temperature was significantly increased over the YRV region in the summer during 2006-16 in comparison to 1985-97, which led to a significantly increased saturation specific humidity over the YRV region (Fig. 13f). The actual specific humidity was also increased over the YRV region in the summer during 2006-16 (Fig. 13h), which however had less increase than the saturation specific humidity (Fig. 13f). Consequently, the surface relative humidity was decreased over the YRV region in the summer during 2006-16 due to the significantly increased saturation specific humidity, which partially contributed to the decreased mei-yu intensity during 2006-16. Similar results are obtained for the differences in relative humidity, air temperature, saturation specific humidity, and actual specific humidity at the 925- and 850-hPa pressure levels.

According to the Clausius-Clapeyron equation, the saturation specific humidity increases more and more dramatically as temperature increases (Held and Soden 

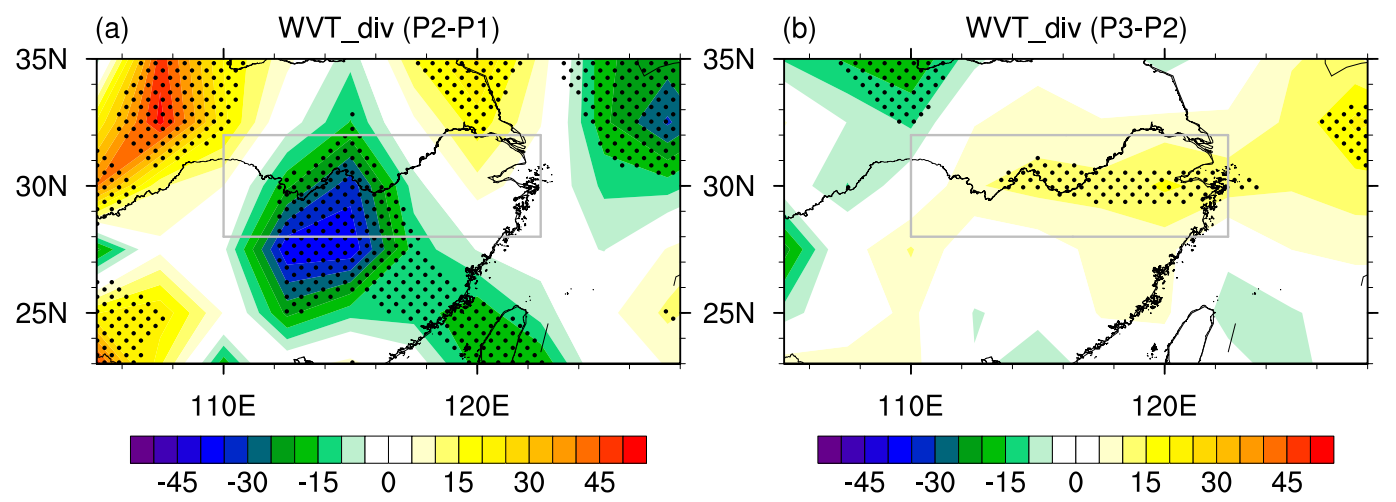

(c)

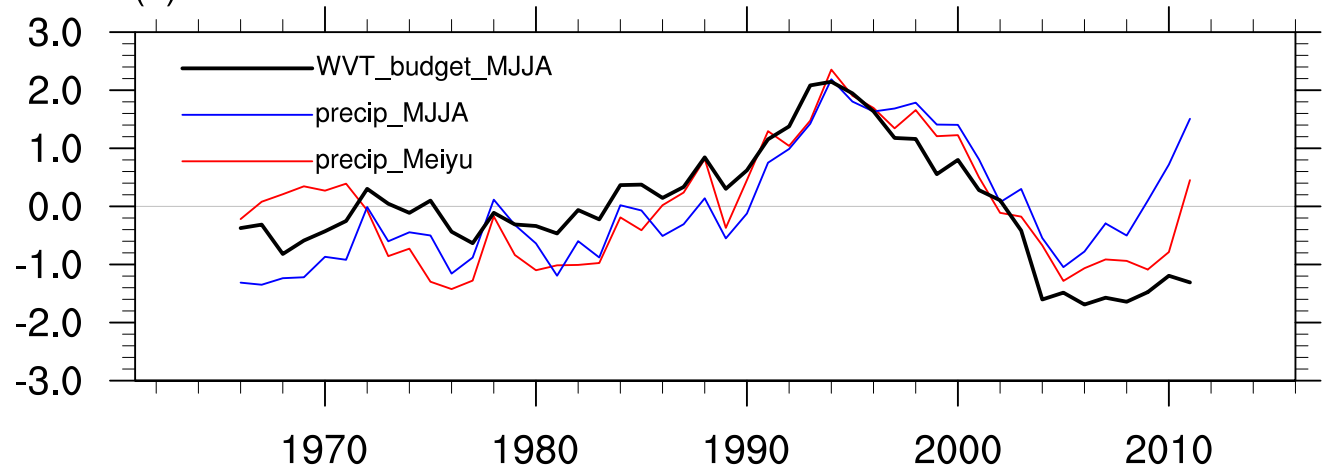

FIG. 12. Differences in divergence of vertically integrated WVT (unit: $10^{-6} \mathrm{~kg} \mathrm{~m}^{-2} \mathrm{~s}^{-1}$ ) (a) between 1961-80 and 1985-97 (latter period minus former period) and (b) between 1985-97 and 2006-16 (latter period minus former period). (c) Standardized 11-yr running mean time series of net water vapor flux over the YRV region (in black), MJJA mean precipitation averaged over the YRV region (in blue), and precipitation averaged over the YRV region for the mei-yu period (15 Jun-10 Jul; in red) during 1961-2016. Stippling in (a) and (b) denotes where the anomalies are significant at the $90 \%$ confidence level based on Student's $t$ test. Gray rectangles in (a) and (b) denote the domain of YRV region.

2006). Hence, the impact of temperature on relative humidity will possibly be more and more significant in the future under global warming ( $\mathrm{Xu}$ and $\mathrm{Xu}$ 2012; Knutti and Sedláček 2013; Y. Xu et al. 2018), which might exert a profound influence on the mei-yu intensity in the future.

\section{Conclusions and discussion}

This study introduced a MVCI to illustrate the synoptic features of mei-yu in the YRV region based on three indicators of mei-yu including precipitation, surface relative humidity, and tropospheric vertical motion. The interdecadal variation in the synoptic-scale features of MVCI indicates that the synoptic features of mei-yu underwent notable interdecadal variations in the date of mei-yu peak and intensity of mei-yu. The delayed (relatively early) mei-yu peak during 1985-97 (1961-80 and 2006-16) may be attributed to a delayed (relatively early) enhancement of southerly WVT over eastern China in the late June. A positive phase of the PDO may induce a weakened clockwise gyre over the North $\mathrm{Pa}$ cific and particularly northerly WVT anomalies over the WNP and eastern China during summer, which impede the enhancement of the southerly WVT anomalies over eastern China along the western flank of the anomalous anticyclone over the WNP in the late June, contributing to a delayed mei-yu peak in the YRV region, and vice versa. The interdecadal variation in mei-yu intensity over past decades is associated with an interdecadal variation in the tropospheric vertical motion over the YRV region during summer, which may be partially attributed to an influence of PDO on the large-scale tropical east-west circulation during summer. The warming in the YRV region after the 1990s partially contributed to the decreased mei-yu intensity after the 1990s due to the increased saturation specific humidity.

In addition to the impact of PDO, other factors may also play a role in modulating the interdecadal variability of the synoptic features of mei-yu, such as the Kuroshio SST front in East China Sea (M. Xu et al. 2018), the cooling in the upper-level atmosphere over 

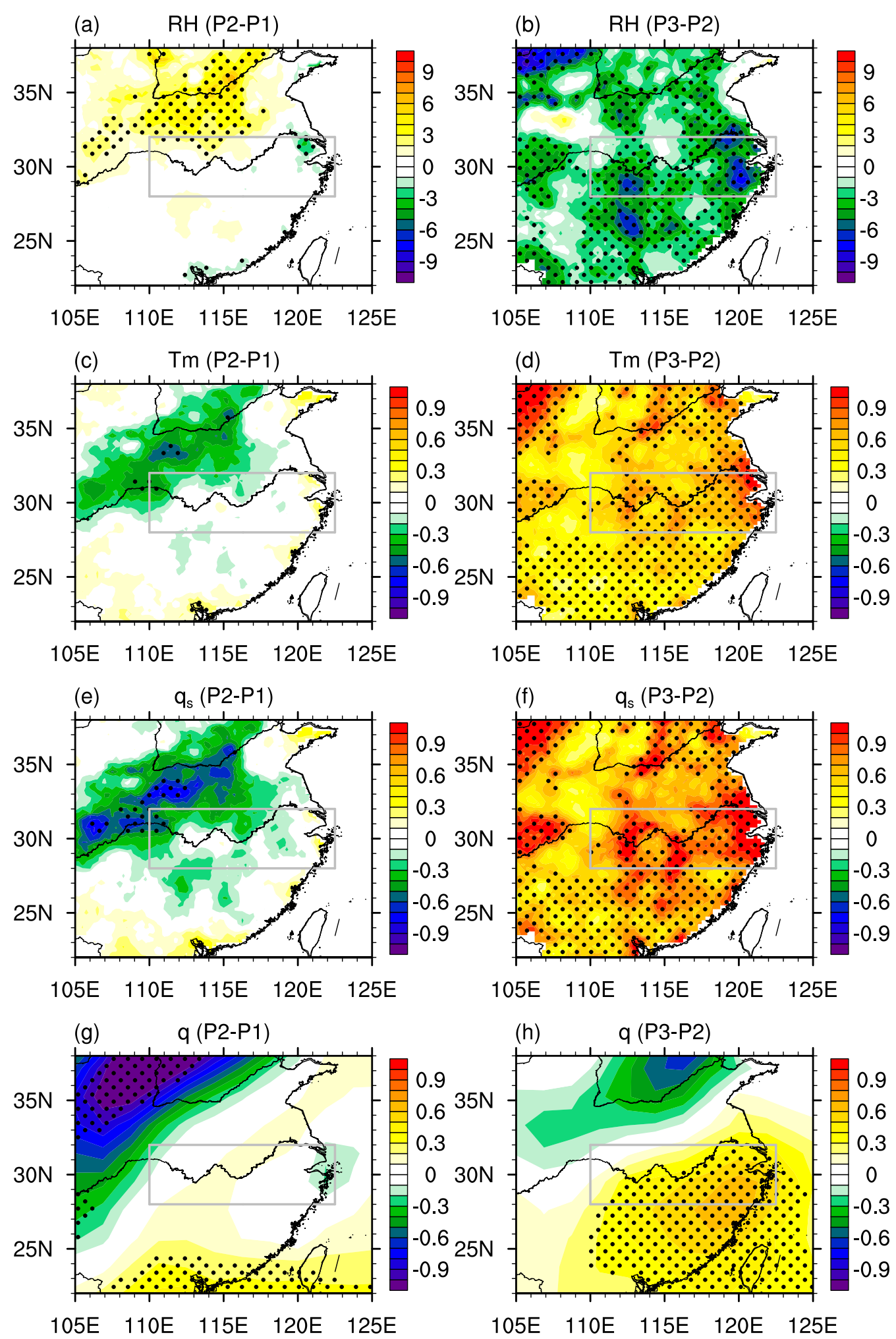

FIG. 13. Differences in MJJA mean (a),(b) surface relative humidity (unit: \%), (c),(d) surface temperature (unit: ${ }^{\circ} \mathrm{C}$ ), (e),(f) surface saturation specific humidity $\left(\mathrm{g} \mathrm{kg}^{-1}\right)$, and $(\mathrm{g}),(\mathrm{h})$ surface specific humidity $\left(\mathrm{g} \mathrm{kg}^{-1}\right)$ : (a),(c),(e),(g) between 1961-80 and 1985-97 (latter period minus former period) and (b),(d),(f),(h) between 1985-97 and 2006-16 (latter period minus former period). Stippling denotes where the anomalies are significant at the $95 \%$ confidence level based on Student's $t$ test. Gray rectangles denote the domain of YRV region. 
midlatitudinal East Asia (Si et al. 2009; Sun and Wang 2017), and the South Asian anticyclone (Li et al. 2019). Particularly, the Atlantic multidecadal oscillation is a predominant mode of the interdecadal variability of the Atlantic SSTs and has a profound impact on the Eurasian climate ( $\mathrm{Lu}$ et al. 2006; Luo et al. 2017). Further studies are needed to provide an insight into the relationship between the interdecadal variability of the synoptic features of mei-yu and these factors.

The warming trend in China might further induce increased saturation specific humidity and hence reduced relative humidity over the YRV region in the future (Xu and Xu 2012), which would possibly contribute to a further reduction in the mei-yu intensity in the future. To date, a considerable uncertainty is detected in the projected summer precipitation in China for the twenty-first century (Chen and Sun 2013; Chen et al. 2014; Wu et al. 2015). Numerical simulations using advanced models are demanded to evaluate the changes in the synoptic features of mei-yu in the future as well their uncertainty (Gao and Giorgi 2017; Giorgi and Gao 2018; Niu et al. 2018).

Finally, it should be noted that the mechanisms of the interannual variability of synoptic features of mei-yu may be partially different from the mechanisms of the interdecadal variability of synoptic features of mei-yu. The climate anomalies associated with the interannual variability of date of mei-yu peak and intensity of mei-yu were computed based on the MVCI for individual years during 1961-2016. The results suggest that on the interannual time scale, a delayed date of the mei-yu peak is associated with negative SST anomalies in the midlatitudinal North Pacific and an anomalous cyclone over the midlatitudinal North Pacific; an increased intensity of mei-yu is associated with an anomalous anticyclone over the WNP, which may be partially attributed to an El Niño decaying summer (Wu et al. 2009; Xie et al. 2009; Sun and Wang 2019) and an influence of the EAP/ PJ teleconnection (Nitta 1987; Huang 1992). In addition, the regional SST in the western Pacific may play a role in modulating the interannual variability of mei-yu intensity (Simmonds et al. 1996). The preconditioning of anomalous climate over the Arctic and Eurasia during the preceding winter and spring might also have an impact on the interannual variability of mei-yu during summer (Gong and Ho 2003; Luo et al. 2016). An indepth study is needed to examine the mechanisms of the interannual variability of synoptic features of mei-yu.

Acknowledgments. This study is funded by the National Natural Science Foundation of China (Grants 41805047 and 41421004), the Natural Science Foundation of Jiangsu Province of China (Grant BK20180807), the Natural Science Foundation of Jiangsu Higher Education Institutions of China (Grant 18KJB170014), the Jiangsu Innovation and Entrepreneurship Team, the Technology Innovation Project for Overseas Talents in Nanjing, and the Priority Academic Program Development of Jiangsu Higher Education Institutions (PAPD).

\section{REFERENCES}

Chen, H., and J. Sun, 2013: Projected change in East Asian summer monsoon precipitation under RCP scenario. Meteor. Atmos. Phys., 121, 55-77, https://doi.org/10.1007/s00703-0130257-5.

,-- , and X. Chen, 2014: Projection and uncertainty analysis of global precipitation-related extremes using CMIP5 models. Int. J. Climatol., 34, 2730-2748, https://doi.org/10.1002/ joc. 3871 .

,-- , and H. Li, 2017: Future changes in precipitation extremes over China using the NEX-GDDP high-resolution daily downscaled data-set. Atmos. Oceanic Sci. Lett., 10, 403 410, https://doi.org/10.1080/16742834.2017.1367625.

Cui, X., S. Gao, H. Zhang, and S. Hao, 2009: A diagnostic analysis of the simulated structure of a Meiyu front system in 1999. Acta Meteor. Sin., 23, 43-52.

Ding, Y., J. Liu, Y. Sun, Y. Liu, J. He, and Y. Song, 2007: A study of the synoptic-climatology of the Meiyu system in East Asia (in Chinese with English abstract). Chin. J. Atmos. Sci., 31, 10821101.

— Z Z. Wang, and Y. Sun, 2008: Inter-decadal variation of the summer precipitation in East China and its association with decreasing Asian summer monsoon. Part I: Observed evidences. Int. J. Climatol., 28, 1139-1161, https://doi.org/10.1002/ joc. 1615.

Gao, X., and F. Giorgi, 2017: Use of the RegCM system over East Asia: Review and perspectives. Engineering, 3, 766-772, https://doi.org/10.1016/J.ENG.2017.05.019.

— conditions over China based on multi-RegCM4 simulations. Atmos. Oceanic Sci. Lett., 11, 291-299, https://doi.org/10.1080/ 16742834.2018.1471578.

Ge, Q., X. Guo, J. Zheng, and Z. Hao, 2008: Meiyu in the middle and lower reaches of the Yangtze River since 1736. Chin. Sci. Bull., 53, 107-114, https://doi.org/10.1007/s11434-0070440-5.

Giorgi, F., and X. Gao, 2018: Regional Earth system modeling: Review and future directions. Atmos. Oceanic Sci. Lett., 11, 189-197, https://doi.org/10.1080/16742834.2018.1452520.

Gong, D. Y., and C. H. Ho, 2003: Arctic Oscillation signals in the East Asian summer monsoon. J. Geophys. Res., 108, 4066, https://doi.org/10.1029/2002JD002193.

Goswami, B., V. Krishnamurthy, and H. Annamalai, 1999: A broad-scale circulation index for the interannual variability of the Indian summer monsoon. Quart. J. Roy. Meteor. Soc., 125, 611-633, https://doi.org/10.1002/qj.49712555412.

He, C., T. Zhou, A. Lin, B. Wu, D. Gu, C. Li, and B. Zheng, 2015: Enhanced or weakened western North Pacific subtropical high under global warming? Sci. Rep., 5, 16 771, https://doi.org/ 10.1038/srep16771.

Held, I. M., and B. J. Soden, 2006: Robust responses of the hydrological cycle to global warming. J. Climate, 19, 5686-5699, https://doi.org/10.1175/JCLI3990.1. 
Hu, Y., H. Huang, and C. Zhou, 2018: Widening and weakening of the Hadley circulation under global warming. Sci. Bull., 63, 640-644, https://doi.org/10.1016/j.scib.2018.04.020.

Huaman, L., and C. Schumacher, 2018: Assessing the vertical latent heating structure of the East Pacific ITCZ using the CloudSat CPR and TRMM PR. J. Climate, 31, 2563-2577, https:// doi.org/10.1175/JCLI-D-17-0590.1.

Huang, B., and Coauthors, 2015: Extended Reconstructed Sea Surface Temperature version 4 (ERSST. v4). Part I: Upgrades and intercomparisons. J. Climate, 28, 911-930, https://doi.org/ 10.1175/JCLI-D-14-00006.1.

Huang, P., D. Chen, and J. Ying, 2017: Weakening of the tropical atmospheric circulation response to local sea surface temperature anomalies under global warming. J. Climate, 30, 8149-8158, https://doi.org/10.1175/JCLI-D-17-0171.1.

Huang, R., 1992: The East Asia/Pacific pattern teleconnection of summer circulation and climate anomaly in East Asia. Acta Meteor. Sin., 6, 25-37.

Huang, Y., and X. Li, 2015: The interdecadal variation of the western Pacific subtropical high as measured by $500 \mathrm{hPa}$ eddy geopotential height. Atmos. Oceanic Sci. Lett., 8, 371-375, https://doi.org/10.3878/AOSL20150038.

— - H. Wang, K. Fan, and Y. Gao, 2015: The western Pacific subtropical high after the 1970s: Westward or eastward shift? Climate Dyn., 44, 2035-2047, https://doi.org/10.1007/s00382014-2194-5.

Jeong, J.-H., B.-M. Kim, C.-H. Ho, and Y.-H. Noh, 2008: Systematic variation in wintertime precipitation in East Asia by MJOinduced extratropical vertical motion. J. Climate, 21, 788-801, https://doi.org/10.1175/2007JCLI1801.1.

Kalnay, E., and Coauthors, 1996: The NCEP/NCAR 40-Year Reanalysis Project. Bull. Amer. Meteor. Soc., 77, 437-471, https:// doi.org/10.1175/1520-0477(1996)077<0437:TNYRP>2.0.CO;2.

Knutti, R., and J. Sedláček, 2013: Robustness and uncertainties in the new CMIP5 climate model projections. Nat. Climate Change, 3, 369-373, https://doi.org/10.1038/nclimate1716.

Krishnamurti, T. N., 1971: Tropical east-west circulations during the northern summer. J. Atmos. Sci., 28, 1342-1347, https://doi.org/ 10.1175/1520-0469(1971)028<1342:TEWCDT>2.0.CO;2.

Li, H., S. He, K. Fan, and H. Wang, 2019: Relationship between the onset date of the Meiyu and the South Asian anticyclone in April and the related mechanisms. Climate Dyn., 52, 209-226, https://doi.org/10.1007/s00382-018-4131-5.

Li, L., and Y. Zhang, 2014: Effects of different configurations of the East Asian subtropical and polar front jets on precipitation during the mei-yu season. J. Climate, 27, 6660-6672, https:// doi.org/10.1175/JCLI-D-14-00021.1.

Li, S., D. Jiang, Y. Lian, and Y. Yao, 2017: Trends in day-to-day variability of surface air temperature in China during 19612012. Atmos. Oceanic Sci. Lett., 10, 122-129, https://doi.org/ 10.1080/16742834.2017.1258291.

Li, Y., Y. Deng, S. Yang, and H. Zhang, 2018: Multi-scale temporospatial variability of the East Asian Meiyu-Baiu fronts: Characterization with a suite of new objective indices. Climate Dyn., 51, 1659-1670, https://doi.org/10.1007/s00382-017-3975-4.

Lu, R., B. Dong, and H. Ding, 2006: Impact of the Atlantic Multidecadal Oscillation on the Asian summer monsoon. Geophys. Res. Lett., 33, L24701, https://doi.org/10.1029/2006GL027655.

_- Y. Li, and C. S. Ryu, 2008: Relationship between the zonal displacement of the western Pacific subtropical high and the dominant modes of low-tropospheric circulation in summer. Prog. Nat. Sci., 18, 161-165, https://doi.org/10.1016/ j.pnsc.2007.07.009.
Luber, G., and M. McGeehin, 2008: Climate change and extreme heat event. Amer. J. Prev. Med., 35, 429-435, https://doi.org/ 10.1016/j.amepre.2008.08.021.

Luo, D., Y. Xiao, Y. Diao, A. Dai, C. L. E. Franzke, and I. Simmonds, 2016: Impact of Ural blocking on winter warm Arctic-cold Eurasian anomalies. Part II: The link to the North Atlantic Oscillation. J. Climate, 29, 3949-3971, https://doi.org/ 10.1175/JCLI-D-15-0612.1.

Y. Chen, A. Dai, M. Mu, R. Zhang, and I. Simmonds, 2017: Winter Eurasian cooling linked with the Atlantic Multidecadal Oscillation. Environ. Res. Lett., 12, 125002, https:// doi.org/10.1088/1748-9326/aa8de8.

Manganello, J. V., and Coauthors, 2012: Tropical cyclone climatology in a 10-km global atmospheric GCM: Toward weatherresolving climate modeling. J. Climate, 25, 3867-3893, https:// doi.org/10.1175/JCLI-D-11-00346.1.

Mantua, N. J., and S. R. Hare, 2002: The Pacific Decadal Oscillation. J. Oceanogr., 58, 35-44, https://doi.org/10.1023/A: 1015820616384.

McGregor, S., A. Timmermann, M. F. Stuecker, M. H. England, M. Merrifiled, F. Jin, and Y. Chikamoto, 2014: Recent Walker circulation strengthening and Pacific cooling amplified by Atlantic warming. Nat. Climate Change, 4, 888-892, https:// doi.org/10.1038/nclimate2330.

Ninomiya, K., and Y. Shibagaki, 2007: Multi-scale features of the Meiyu-Baiu front and associated precipitation systems. J. Meteor. Soc. Japan, 85B, 103-122, https://doi.org/10.2151/jmsj.85B.103.

Nitta, T., 1987: Convective activities in the tropical western Pacific and their impact on the Northern Hemisphere summer circulation. J. Meteor. Soc. Japan, 65, 73-390, https://doi.org/ 10.2151/jmsj1965.65.3_373.

Niu, X., and Coauthors, 2018: Ensemble evaluation and projection of climate extremes in China using RMIP models. Int. J. Climatol., 38, 2039-2055, https://doi.org/10.1002/joc.5315.

Norris, J. R., and S. F. Iacobellis, 2005: North Pacific cloud feedbacks inferred from synoptic-scale dynamic and thermodynamic relationships. J. Climate, 18, 4862-4878, https://doi.org/ 10.1175/JCLI3558.1.

Rhome, J. R., D. S. Niyogi, and S. Raman, 2000: Mesoclimatic analysis of severe weather and ENSO interactions in North Carolina. Geophys. Res. Lett., 27, 2269-2272, https://doi.org/ 10.1029/1999GL011327.

Robinson, P. J., 2001: On the definition of a heat wave. J. Appl. Meteor., 40, 762-775, https://doi.org/10.1175/1520-0450(2001) $040<0762$ :OTDOAH $>2.0 . \mathrm{CO} ; 2$.

Sampe, T., and S. Xie, 2010: Large-scale dynamics of the Meiyu-Baiu rainband: Environmental forcing by the westerly jet. J. Climate, 23, 113-134, https://doi.org/10.1175/2009JCLI3128.1.

Shen, C., W. Wang, Z. Hao, and W. Gong, 2007: Exceptional drought events over eastern China during the last five centuries. Climatic Change, 85, 453-471, https://doi.org/10.1007/ s10584-007-9283-y.

Si, D., H. Xu, M. Wen, and J. He, 2008: Analysis of the westward extension of western Pacific subtropical high during a heavy rain period over southern China in June 2005. J. Trop. Meteor., 14, 93-96.

Y. Ding, and Y. Liu, 2009: Decadal northward shift of the Meiyu belt and the possible cause. Chin. Sci. Bull., 54, 47424748, https://doi.org/10.1007/s11434-009-0385-y.

Simmonds, I., D. Bi, and B. Yan, 1996: Relationships between summer rainfall over China and ocean temperatures in the tropical western Pacific. J. Meteor. Soc. Japan, 74, 273-279, https://doi.org/10.2151/jmsj1965.74.2_273. 
, and P. Hope, 1999: Atmospheric water vapor flux and its association with rainfall over China in summer. J. Climate, 12, 1353-1367, https://doi.org/10.1175/1520-0442(1999)012<1353: AWVFAI $>2.0 . \mathrm{CO} ; 2$.

Song, Y., Y. Liu, and Y. Ding, 2012: A study of surface humidity changes in China during the recent 50 years. Acta Meteor. Sin., 26, 541-553, https://doi.org/10.1007/s13351-012-0501-9.

Sun, B., 2018: Asymmetric variations in the tropical ascending branches of Hadley circulations and the associated mechanisms and effects. Adv. Atmos. Sci., 35, 317-333, https:// doi.org/10.1007/s00376-017-7089-z.

— , and H. Wang, 2015: Inter-decadal transition of the leading mode of inter-annual variability of summer rainfall in East China and its associated atmospheric water vapor transport. Climate Dyn., 44, 2703-2722, https://doi.org/10.1007/s00382014-2251-0.

_, and _ 2017: A trend towards a stable warm and windless state of the surface weather conditions in northern and northeastern China during 1961-2014. Adv. Atmos. Sci., 34, 713-726, https://doi.org/10.1007/s00376-017-6252-x.

— summer precipitation over the Three River Source region in China and the associated regimes. J. Climate, 31, 7441-7457, https://doi.org/10.1175/JCLI-D-17-0680.1.

— precipitation over the Three-River-Source region China and the global climate system. Climate Dyn., 52, 3471-3488, https:// doi.org/10.1007/s00382-018-4326-9.

—, Y. Zhu, and H. Wang, 2011: The recent interdecadal and interannual variation of water vapor transport over eastern China. Adv. Atmos. Sci., 28, 1039-1048, https://doi.org/10.1007/ s00376-010-0093-1.

Tanaka, H., and Coauthors, 2007: Surface flux and atmospheric boundary layer observations from the LAPS project over the middle stream of the Huaihe River basin in China. Hydrol. Processes, 21, 1997-2008, https://doi.org/10.1002/hyp.6706.

Tokinaga, H., S. Xie, C. Deser, Y. Kosaka, and Y. M. Okumura, 2012: Slowdown of the Walker circulation driven by tropical Indo-Pacific warming. Nature, 491, 439-443, https://doi.org/ 10.1038/nature11576.

Trenberth, K. E., 2011: Changes in precipitation with climate change. Climate Res., 47, 123-138, https://doi.org/10.3354/cr00953.

Vecchi, G. A., and B. J. Soden, 2007: Global warming and the weakening of the tropical circulation. J. Climate, 20, 4316-4340, https://doi.org/10.1175/JCLI4258.1.

Wang, H., 2001: The weakening of the Asian monsoon circulation after the end of 1970's. Adv. Atmos. Sci., 18, 376-386, https:// doi.org/10.1007/BF02919316.

Wang, J., J. He, X. Liu, and B. Wu, 2009: Interannual variability of the Meiyu onset over Yangtze-Huaihe River valley and analyses of its previous strong influence signal. Chin. Sci. Bull., 54, 687-695, https://doi.org/10.1007/s11434-008-0534-8.

Wang, M., and J. Paegle, 1996: Impact of analysis uncertainty upon regional atmospheric moisture flux. J. Geophys. Res., 101, 7291-7303, https://doi.org/10.1029/95JD02896.

Wu, B., T. Zhou, and T. Li, 2009: Seasonally evolving dominant interannual variability modes of East Asian climate. J. Climate, 22, 2992-3005, https://doi.org/10.1175/2008JCLI2710.1.
Wu, J., and X. Gao, 2013: A gridded daily observation dataset over China region and comparison with the other datasets (in Chinese with English abstract). Chin. J. Geophys., 56, 1102-1111.

,,-- Y. Xu, and J. Pan, 2015: Regional climate change and uncertainty analysis based on four regional climate model simulations over China. Atmos. Oceanic Sci. Lett., 8, 147-152, https://doi.org/10.3878/AOSL20150013.

Wu, R., Z. Wen, S. Yang, and Y. Li, 2010: An interdecadal change in southern China summer rainfall around 1992/93. J. Climate, 23, 2389-2403, https://doi.org/10.1175/2009JCLI3336.1.

Wyant, M. C., C. S. Bretherton, J. T. Bacmeister, J. T. Kiehl, I. M. Held, M. Zhao, S. A. Klein, and B. J. Soden, 2006: A comparison of low-latitude cloud properties and their response to climate change in three AGCMs sorted into regimes using mid-tropospheric vertical velocity. Climate Dyn., 27, 261-279, https://doi.org/10.1007/s00382-006-0138-4.

Xie, S. P., K. Hu, J. Hafner, H. Tokinaga, Y. Du, G. Huang, and T. Sampe, 2009: Indian Ocean capacitor effect on Indowestern Pacific climate during the summer following El Niño. J. Climate, 22, 730-747, https://doi.org/10.1175/ 2008JCLI2544.1.

$\mathrm{Xu}, \mathrm{C}$., and $\mathrm{Y} . \mathrm{Xu}, 2012$ : The projection of temperature and precipitation over China under RCP scenarios using a CMIP5 multi-model ensemble. Atmos. Oceanic Sci. Lett., 5, 527-533, https://doi.org/10.1080/16742834.2012.11447042.

Xu, M., H. Xu, and H. Ren, 2018: Influence of Kuroshio SST front in the East China Sea on the climatological evolution of Meiyu rainband. Climate Dyn., 50, 1243-1266, https://doi.org/ 10.1007/s00382-017-3681-2.

Xu, Y., X. Gao, Y. Shen, C. Xu, Y. Shi, and F. Giorgi, 2009: A daily temperature dataset over China and its application in validating a RCM simulation. Adv. Atmos. Sci., 26, 763-772, https://doi.org/10.1007/s00376-009-9029-z.

,-- , F. Giorgi, B. Zhou, Y. Shi, J. Wu, and Y. Zhang, 2018: Projected changes in temperature and precipitation extremes over China. Adv. Atmos. Sci., 35, 376-388, https://doi.org/ 10.1007/s00376-017-6269-1.

Yang, R., Z. Xie, and J. Cao, 2017: A dynamic index for the westward ridge point variability of the western Pacific subtropical high during summer. J. Climate, 30, 3325-3341, https:// doi.org/10.1175/JCLI-D-16-0434.1.

Zhao, J., and Y. Han, 2005: Estimation of correlation significance levels after moving average. J. Beijing Normal Univ., 41, 139-141.

Zhou, T., and Coauthors, 2009: Why the western Pacific subtropical high has extended westward since the late 1970s. J. Climate, 22, 2199-2215, https://doi.org/10.1175/2008JCLI2527.1.

Zhou, Y., S. Gao, and S. Shen, 2004: A diagnostic study of formation and structure of the Meiyu front system over East Asia. J. Meteor. Soc. Japan, 82, 1565-1576, https://doi.org/ 10.2151/jmsj.82.1565.

Zhu, Y., H. Wang, W. Zhou, and J. Ma, 2011: Recent changes in the summer precipitation pattern in East China and the background circulation. Climate Dyn., 36, 1463-1473, https:// doi.org/10.1007/s00382-010-0852-9.

,-- J. Ma, T. Wang, and J. Sun, 2015: Contribution of the phase transition of Pacific Decadal Oscillation to the late 1990s' shift in East China summer rainfall. J. Geophys. Res. Atmos., 120, 8817-8827, https://doi.org/10.1002/2015JD023545. 